\title{
What is digital parenting? A systematic review of past measurement and blueprint for the future
}

\author{
Kathryn L. Modecki \\ Griffith University
}

\author{
Pamela Wisniewski \\ University of Central Florida
}

\author{
Rachel Goldberg \\ University of California Irvine
}

\author{
Amy Orben \\ University of Cambridge
}

\begin{abstract}
Concerns about parenting adolescents are not new, but the rapid diffusion of digital technologies has heightened anxieties over digital parenting. Findings are decidedly mixed regarding the impact of digital technologies on adolescent wellbeing, and parents are left to navigate their concerns without an empirically based road map. A missing link for understanding the state of the science is a clear characterization of how digital parenting is measured, including an evaluation of which areas demand an outsized share of scientific attention, and which have been overlooked. To address this gap, we undertook two interdisciplinary systematic reviews of the digital parenting literature and characterized measurement across a) quantitative surveys $(n=145$ studies) and $b)$ qualitative focus groups and interviews $(n$ $=49$ studies). We describe previously popular areas of survey measurement that are of decreasing relevance to parenting of digital spaces (e.g., co-use, hovering). We likewise highlight areas that have been overlooked, including consideration of positive uses of digital technologies, acknowledgement of bi-directional influence, and attention to heterogeneity among families and to extra-parental social ecologies of support and monitoring. We provide recommendations for the future of digital parenting research, proposing a more comprehensive approach to measuring how we parent modern adolescents.
\end{abstract}

Keywords: Development; Adolescence; Interpersonal Relations; Digital Parenting; Technology Use

\section{Limiting your child's fire time: a guide for concerned palaeolithic parents}

It's important to make sure that your child engages in other activities, like mammoth hunting and the gathering of rocks and bones with which to make tools."

Rachel Klein, New Yorker

(February 7, 2018)

One indicator that an issue has captured societal attention is when it becomes the target of satire. Concerns about parenting in the digital age reached this point in 2018, when Rachel Klein wrote a New Yorker caricature about "limiting your child's fire time." Taking the perspective of a Paleolithic parent, Klein first acknowledges the many beneficial applications of a "new" technology: in this case, fire. She then asserts that while adults who were born before fire's advent can readily moderate their use, many children may struggle with self-monitoring their fire-time.
Just like such prehistoric technology, today's digital innovations afford parents and children with many useful applications (Livingstone et al., 2018; Heron \& Smyth, 2010; McClure et al., 2018; Modecki et al., 2021a; Moreno \& Uhls, 2019). However, as Klein satirizes in her piece, many parents fear new digital technologies could potentially harm their children (George \& Odgers, 2015; Modecki et al., 2021b; Radesky et al., 2016). These concerns have magnified over the last years, with digital technologies taking up increasing amounts of children and adolescents' time and creeping into ever more areas of life (Odgers \& Jensen, 2020). In 2018 , almost $50 \%$ of US teens stated that they are "almost constantly" online (Anderson \& Jiang, 2018) and this percentage has risen substantially over the past years as much of daily life has moved onto digital technological spaces during the global COVID-19 pandemic (Ofcom, 2020).

Concerns about the impact of this rapid digitalization on children and adolescents are routinely voiced in both the scientific literature and popular press (Bell et 
al., 2015; Twenge, 2019) and have been the subject of medical and political inquiries (Hawkes, 2019; House of Commons Science and Technology Select Committee, 2019). While some researchers purport a negative causal link between time spent on digital technologies and adolescent well-being (Twenge et al., 2018), others have voiced concern that the evidence is not currently strong enough to warrant such conclusions (Hefferet al., 2019; Orben \& Przybylski, 2019b). Indeed, many studies have found mixed or inconclusive evidence (Allcott et al., 2019; Jensen et al., 2019; Kreski et al., 2020; Orben \& Przybylski, 2019a), and reviews have highlighted the lack of consistent findings in an area where the impact is probably governed largely by individual differences and complex interactions (Beyens et al., 2020; Dienlin \& Johannes, 2020; Hawkes, 2019; Odgers \& Jensen, 2020; Orben, 2020a).

Various organizations note the growing chasm between the evidence provided by the scientific literature and what is needed to create evidence-based guidelines about adolescent digital technology use and how parents should respond (Hawkes, 2019; Viner et al., 2019). Digital parenting behaviors are multifaceted and complex, including, for example, the monitoring of adolescent technology use, rule provision, and enforcement; education and promotion of digital skills; navigation of online education; and the exploitation of online opportunities (Odgers, 2019). Yet there are currently no upto-date technology- and developmentally- focused tools, including questionnaires, to study this complex behavior. In the absence of questionnaires developed explicitly to understand contemporary digital parenting, researchers are left to repurpose existing measures, most of which were developed for older technologies such as the home television, or are left to design improvised items without the necessary validation processes.

This is hazardous territory. The evidence gap, missing future research vision, and outdated measures necessary to understand and guide digital parenting leave parents largely unaided in seeking to navigate a rapidly developing space. Changing digital technologies mean facing constantly new and different challenges for parents, which they are forced to address in the absence of evidence-based guidance. Most recently, parents have needed to navigate school-driven mandates for laptopbased learning and pandemic disruptions to in-person education, leisure, and social life. A Pew Research survey administered in March 2020 found that two-thirds of US parents considered parenting harder today than it was 20 years ago; unsurprisingly, many attribute this development to new technologies such as smartphones and social media (Auxier et al., 2020). Faced with this growing challenge, many parents attempt to safeguard children by setting rules about or monitoring the use of technologies. Parents hope that by tamping-down on adolescents' use and over-seeing their online activities, they might avoid largely undefined, yet decidedly negative consequences (Lanette et al, 2018). Yet this approach risks hamstringing children's own developmental needs, by curtailing opportunities to gain developmental experiences and learn important digital skills (Hunter et al., 2011; Soenens et al., 2007).

In this review, we aim to provide parents and researchers with the knowledge base they need to understand the complexity of digital parenting, alongside a blueprint for future digital parenting research. To do so, we first summarize prior psychological approaches to parenting adolescents and evaluate the problems parents face in raising adolescents during a time of rapid technological change. We present current approaches to studying digital parenting using frameworks developed in media studies and communication sciences, and then report findings from an interdisciplinary systematic review examining how digital parenting has been measured and quantified to date. Subsequently, we present results from our complementary interdisciplinary systematic review of the qualitative literature studying digital parenting, focused on identifying key areas which the current quantitative measurement of digital parenting has neglected or over-emphasized. Our interpretation of the research landscape that follows summarizes these important insights and pinpoints opportunities for improved, developmentally-informed psychological research on parenting in the digital age.

\section{Essential Parenting Challenge: Fostering Both In- dependence and Safety}

A fundamental developmental task in adolescence is to begin functioning as an autonomous individual. Adolescents must learn how to take responsibility for themselves and their choices in order to progress towards a healthy and independent adulthood (Soens et al., 2007). This means navigating new relationships and peers, novel situations and untried possibilities which mold adolescents' value system and shape their eventual independent identity (Allen et al., 1996; Collins et al. 1997; Smetana \& Asquith, 1994). Such autonomous functioning is part of a healthy transition to adulthood, regardless of whether youth are navigating these tasks face-to-face or digitally.

Tasked with nurturing this growing independence, parents and caregivers face their own balancing act. 
They seek to confer youth the independence and autonomous functioning needed to achieve psychosocial maturity, while providing sufficient monitoring and support to keep youth safe (Erickson et al., 2016). How this tension is navigated - between independence on the one hand, and safety on the other-has long term implications for the parent-child relationship and for adolescents' development.

This challenge is not new and applies to both the offline and online realm. Indeed, decades of research have explored the successful management of the parent-child relationship during adolescence. With the onset of puberty, youth traditionally spend less and less time at home and more time with peers, leaving parents with fewer opportunities for direct supervision (Lam et al., 2014; Larson \& Richards, 1991; Larson et al., 2002; Updegraff et al. 2006). Parents can respond to this development is several different ways. They might implement "control strategies," such as requiring adolescents to seek permission to go "out," asking them to provide information about the level of adult supervision at their destination, or requesting that they disclose who they are spending time with, what they are doing, and/or when they will return home (Kerr \& Stattin, 2000). Parents might alternately employ "solicitation strategies," gathering information about what is happening in their adolescents' lives by asking them about their experiences, a technique which relies on adolescents' own willingness to share information. Adolescents will only be forthcoming if they trust in their ability to confide in adults without recrimination (Crouter et al., 2005).

Parents might also elect to foster relationships in which their children disclose information on their own accord, in order to help adolescents navigate their transition into independence (Smetana et al., 2006; Tokić $\&$ Pećnik, 2011). This approach is generally considered more positive than control or solicitation strategies, as some developmental theories argue that vigilant surveillance and active tracking are tied to poorer youth outcomes, in part because adolescents may come to doubt their capacity to make good decisions on their own accord if monitored too closely (Fletcher et al., 2004; Hunter et al., 2011). When youth self-disclose voluntarily, this is not only healthier for their adjustment, being tied to higher wellbeing and lower risky behavior (Hamza \& Willoughby, 2011; Soenens et al; 2006; Vieno et al.; 2009), but also more effective as parents tend to learn more about adolescents' activities through voluntary self-disclosure (Kerr \& Stattin, 2000). The goal for parents of adolescents is therefore to develop their child's independence while maintaining good knowledge of their activities: knowledge that ideally stems from a close, positive relationship in which adolescents feel open to disclose (Blodgett Salafia, et al., 2009).

\section{Parenting Television Use}

Despite robust evidence, this developmental understanding that parent-child relationship quality is crucial to balancing adolescents' needs for safety and autonomy has not yet permeated the science of digital parenting. Rather, a focus on adults' behavioral mitigation of risks, and, to a lesser extent, quality of interpersonal communication, formed the foundation for many of the first detailed explorations of parenting technologies (Clark, 2011). Inspired by Bandura's (1978) social learning theory and its focus on parental modelling, researchers approached this work by routinely putting the parent (as opposed to the adolescent, or the parent-adolescent relationship) in the foreground of their research (Clark, 2013). In doing so, lines of scientific inquiry focused on trying to understand parental "doing" behaviors that in turn might help ensure youth safety and wellbeing in response to new technologies.

Foundational work on parental mediation of children's television viewing undertaken by Valkenburg and colleagues (1999) identified three cornerstone parental mediation strategies, based on a descriptive synthesis of communication research up until the 1990's: restrictive mediation, instructive mediation, and social co-viewing. Restrictive mediation, also known as "rule making," encompassed parents setting boundaries and limiting television use. For example, parents might set time limits for viewing or restrict adolescents from viewing specific content. Instructive mediation, also known as "active" or "interpretive" mediation, involved caregivers discussing media use or viewing media content with youth in order to inform their future viewing or behavior. For instance, parents engaging in active mediation might highlight to their children that certain aspects of a television program are unrealistic, either during or after viewing. Finally, social co-viewing referred to parents co-watching media content with their child but without engaging in content discussion. Notably, this type of co-viewing has been associated with enhanced feelings of closeness (Courtois \& Nelissen, 2018).

It is worth noting that Valkenburg and colleagues went to considerable lengths to highlight ways in which "media parenting" could reduce prominent risks of television viewing, as well as enhance its potential benefits (1999). Illustratively, instructive mediation might modify attitudes toward television violence (a potential 
risk from media consumption) or bolster acceptance of non-traditional gender roles (a potential benefit of media consumption). The digital parenting lens has arguably narrowed since this time, with an increasingly predominant focus on parenting as a means of solely combating the risks of technology use, and not as a way to maximize benefits (e.g., Nielsen et al., 2019).

\section{Shifting from TV to Digital Technology}

Despite marked changes in technology use since the turn of the millenium, Valkenburg et al.'s (1999) tripartite typology of restrictive mediation, instructive mediation, and social co-viewing remains predominate in the literature examining digital parenting. It is still the main way in which researchers conceptualize and measure parenting of newer technologies, including youths' use of the internet in general (Livingstone et al., 2017), screens (Nielsen et al., 2019), smartphones (Hwang et al., 2017; Wisniewski et al., 2017), tablets (Beyens \& Beullens, 2017), smart speakers (Garg \& Sengupta, 2020), social media (Hamilton et al., 2020), and online gaming (Koning et al., 2018).

Even in seeking to devise updated parenting measures, the three typologies often re-appear without much additional context or theory specific to the online space. Eastin and colleagues (2006), for example, aimed to design a measure of parental mediation of online content which measured restrictions on time and content of home internet use, as well as what they referred to as "technological mediation," in which parents use software to track their child's internet use. Shifting the Valkenburg typology to the internet, they defined instructive mediation as the evaluation and discussion of online content with adolescents and described co-viewing as experiencing online content alongside one's child. Noting the narrow scope of these definitions in their translation to internet parenting, the authors themselves admitted that employing scales originally conceptualized for television in the context of the internet may be problematic (Eastin et al., 2006).

Continued reliance on applying such older measures to new technologies means that key differences between older and newer technological developments are not acknowledged nor examined (Chassiakos et al., 2016). For example, co-viewing while watching television is arguably far more common than co-viewing when browsing the internet (Eastin et al., 2006). When parenting adolescents' internet use, parents are often left facing a proverbial "black box," one in which they may know relatively little about what activities their child is engaging in. As a result, parents may feel a loss of control over the process of affording youth greater freedoms. For example, in a study by Gomez (2018), a parent shared that "if we put a lot of pressure on her, she's not going to do things in front of us, so then, we won't know what she is doing."

Furthermore, modern digital technologies are far more interactive than their predecessors, with children acting as both consumers and producers of content for increasingly public audiences (Verduyn et al., 2020). No longer is content solely about youths' own media intake - the output is perhaps even more important (Verduyn et al., 2020). This presents both opportunities for development and prosociality (Jones \& Mitchell, 2016) but also new risks, such as the possibility of interacting with unsafe individuals (Jones et al., 2013).

Lastly, digital technologies are more ubiquitous than older technologies, facilitate increasingly intensive and extensive contact with others (Blackwell et al., 2016), and are often used simultaneously with other digital devices (Anderson and Jiang, 2018). Their omnipresence means that the boundaries between online and offline are also increasingly blurred (Anderson and Jiang, 2018). One could even argue that adolescent life is now "post-digital," meaning that the differentiation between online and offline worlds no longer applies (Taffel, 2016). Across the course of daily life, adolescents engage with friends, immerse themselves in school-based activities, and build their complex identities and sense of selves in simultaneous and connected contexts across both online and offline spaces (Jandrić et al., 2016; Vijayakumar \& Pfeifer, 2020). Adolescents are therefore not only fully immersed in the online world, but their development occurs both online and offline, in a bidirectional and fluid manner. From a parent's perspective, this situation means that much of youths' (post-) digital developmental experience is increasingly opaque (Erickson et al., 2016).

\section{The Problem of Measurement}

To address these changes in digital parenting brought about by the advent of modern digital devices and an increasingly immersive online world, researchers have been seeking new ways of measuring digital parenting. Some have sought to augment existing parental monitoring scales with responses for "online" contexts (Law et al., 2010), often by adding an "online" option to an existing scale. Yet this does not ensure va- 
lidity, and there is little to suggest that adding an additional domain to prior measures taps into the experience of adolescents and parents today.

Other scholars have been left to generate self-standing items to tap behaviors such as disclosure of cyber bullying, keeping passwords private, or technology "addiction" (e.g., Nikken \& Jansz, 2006; Wang et al., 2005). Such "on-the-fly" scales however also often lack measurement quality, having low reliability or lacking measurement invariance. They therefore hinder scientific progress and are susceptible to poor or inadequate characterizations of modern family experiences (Flake et al., 2017). Key parenting dimensions, including autonomy building and support, are routinely overlooked within these stopgap operationalizations. As the arena of digital parenting directly feeds into recommendations and advice to whole populations of parents, the field's issues with reliable and valid measurement are especially troublesome.

\section{Previous Reviews and Re-Conceptualizations of Digital Parenting}

Dramatic changes in the technology and parenting landscape have led Valkenburg (Valkenburg et al., 2021) and other digital scholars (Beyens et al, 2020; Odgers, 2018) to call for re-conceptualizations of digital parenting. While several attempts to develop new approaches to conceptualizing digital parenting have been published, these lack sufficient scope to fully recharacterize the state of digital parenting and fail to use systematic approaches. To use vernacular from the field of human-computer interaction, in some ways these studies "pave the cow-path;" in other words, they are following traditional ways of conceptualizing problems, rather than taking a holistic approach to reappraise the wider spectrum of parenting in the digital age.

There are very few systematic reviews or metaanalyses aiming to understand parenting in the digital age. For example, Chen and Shi (2019) conducted a meta-analysis of 52 studies to understand how the three traditional forms of parental mediation proposed by Valkenburg influence youth media use and online risk exposure. They found that restrictive mediation reduced overall time spent on media, while active mediation and co-use were more effective in reducing media-related risks. However, over a third of included studies focused on television viewing, and, in line with previous approaches, the focal point was exclusively on risk mitigation. As a second example, Jago et al. (2013) surveyed 29 studies on media parenting and youth screen-viewing (e.g., television, internet, and gaming) in relation to adolescent obesity. They categorized media parenting as the dichotomy between rule-based and non-rule-based practices and found that most of the studies failed to demonstrate construct validity and/or internal consistency of the measures that were used. As a result, it was difficult, if not impossible, to synthesize results across studies. They therefore called for the development of new measures informed by qualitative research to understand contemporary media parenting practices.

Indeed, numerous scholars have now called for updated measurement of digital parenting, perhaps the most notable among them being Valkenberg and colleagues (2013). Based on Deci and Ryan's (2000) autonomy support in parenting model, they sought to develop a perceived parental mediation scale, which was originally intended to capture internet use, as well as $\mathrm{TV}$, movies, and digital games. The objective was not only to understand parents' behaviors but more importantly, to gauge parents' explanatory style, encouragement of children's' opinions, and responses to noncompliance. However, subsequent challenges with reliability and validity resulted in their only obtaining an abbreviated set of items, which did not include any items concerning adolescents' internet use.

In a somewhat similar example, Jiow and colleagues (2017) more recently asserted a need to "refresh" definitions of parental mediation, including strategies that parents introduce to maximize benefits and minimize potential negative impacts of media influences. They highlight that, due to the greater complexity of the digital media landscape, parental mediation strategies designed around television use are no longer sufficient. To narrowly examine these complexities, however, their new scale ultimately focused solely on video games. Consequently, there remains an urgent need for a more nuanced, holistic, cohesive, and developmentally informed view of contemporary digital parenting.

\section{The Importance of Considering Diversity in Digital Parenting Research}

Among the most vexing issues that a reconceptualization of digital parenting needs to address is heterogeneity among families (e.g., Hankerson et al., 2016; Modecki et al., 2021b; Sugie, 2018). As described by Schlesinger and colleagues (2017), understanding the "user" of technology means acknowledging the different, overlapping attributes of a given user's identity. While scholars of human computer interaction and dig- 
ital race have historically pointed to race and class differences in both how families make use of technology and in norms and expectations regarding technology's benefits and risks, such variation is all too rarely considered within the psychological literature (Allison et al. 2012; London et al., 2010).

Population-based surveys and ethnographies have shown that technology usage looks markedly different depending on socioeconomic status (Lauricella et al., 2016; Pater et al., 2015; Yardi \& Bruckman, 2012). For instance, in the US, low-income homes are significantly more likely to be "smartphone only" households without broadband internet (Vogels, 2021). These families rely on smartphones for tasks typically designed for larger screens, sometimes referred to as the "homework gap" for youth who turn to phone screens for their course work and out of school study (Vogels, 2021). Within lower-income or homeless families it is also not unusual for youth to resort to accessing educational technology at friends' homes and at schools and libraries (Harpin et al, 2016). In 2015, smartphone only homes represented $35 \%$ of US lower income households with school age children (Anderson \& Perrin, 2018); yet the predominate narrative in developmental psychology remains that of risks related to overuse, such as phone addiction, cyberbullying, and the like (Kardefelt-Winther, 2014; Olweus, 2012). At the time of their early scale development, both Valkenberg (1999) and Eastin and colleagues (2006) described potential differences in parental mediation based on SES, suggesting that a through-line conceptualizing such heterogeneity has since been lost. Addressing this incomplete characterization of family technology use requires both the employment of more diverse samples and measurement designed to capture such heterogeneity (Bornstein et al., 2013).

Parents also diverge in their hierarchies of concerns and parenting styles (Erickson et al., 2016), and technology use is by no means at the apex of worries for some families, especially those from marginalized contexts, such as foster families (Badillo-Urquiola et al., 2019). For example, lower income families have tended to view television as an accompaniment to everyday life, often contributing to family harmony, while higher income families have tended to have more concerns regarding negative influences (Clark, 2011). More recently, research has found that low socioeconomic status families both more frequently share devices and give youth more autonomy over their own technology use (Yardi \& Bruckman, 2012), such that concerns about monitoring may be less prevalent (Lauricella et al., 2016). As one example, within low-income Latino homes in the US, it is common for children to lead their family's efforts to access online information, much the same way these youth are known to act as "knowledge brokers" offline within bilingual families (Pina et al, 2018). As a result, joint media engagement is relatively common in these families, but the impact on wellbeing of such collective use remains unknown (Pina et al., 2018).

Research agnostic to such heterogeneity in family experiences, norms and priorities may arguably give rise to a misleading picture of digital parenting. White middle-class samples are often held as the "normative" expectation, ignoring heterogeneity in availability of technologies, in expectations and realities with respect to where and how youth gain access to digital devices, and in family privacy norms. Arguably, much past research - and particularly the research that has been most influential in the development of digital parenting measures - has glossed over these types of compelling differences in families' technology experiences and digital parenting. As a result, scholars have called for digital media scholarship grounded in ethnographic and digital race perspectives as well as a more integrated discussion of heterogeneity across the digital parenting literature (e.g., Benjamin, 2019; Clark, 2011; Ellison et al., 2017; Noble, 2018).

\section{Towards a New Account in a Post-Digital Age}

Current approaches to understanding how parents monitor and support adolescent development in the digital age are arguably antiquated, fragmented, and riddled with ad hoc measurement. Yet the way we conceptualize, study, and understand the interface of parenting and technology is becoming ever more critical as the time adolescents spend using digital technologies continues to rise and parental concerns continue to grow (Anderson \& Jiang, 2018; Ofcom, 2017). Digitalization is only expected to continue in the future, meaning that a functional approach to digital parenting, and accurate measurement of such parenting, will become increasingly important if psychology is to support this area of contemporary concern.

As a result, it is critical to take stock of existing measures of digital parenting to understand where current work is falling short and offer a blueprint for ways to move our science forward. Arguably, measures need to correspond to actual adolescent technological behaviors and actual digital parenting strategies. They need to capture both the spectrum of potential affordances from technology, whether negative or positive, as well 
as heterogeneity in technology use, parenting strategies, and parental approaches to technology.

To address the provisional status of measurement within the field, we took an interdisciplinary, novel approach to systematically inventory and reflect on the many ways in which scholars have recently sought to measure and understand parental monitoring and support in relation to adolescents' technology use. The scope of this review was designed to encompass multiple fields: psychology, sociology, media and communication studies, as well as conference proceedings related to human-computer interaction and computer science. To better understand the breadth of digital parenting, we first systematically reviewed survey-based research, both published and unpublished, to catalogue the array of items and scales that researchers have been using to operationalize digital parental monitoring and support. Then, to ensure we captured the full scope of digital parenting, beyond what is currently tapped via quantitative scales, we further undertook a systematic complementary review of the qualitative research assessing parenting adolescents' technology use, a scoping exercise that included focus groups, interviews, and open-ended responses to parenting questions. This allowed us to identify constructs neglected, under-emphasized, or over-emphasized in survey research to date and put forward a new blueprint for measuring digital parenting.

\section{Review of Survey Measurement of Digital Par- enting}

\section{Identification of the Literature}

Both our reviews of the survey-based and qualitative literatures followed the PRISMA guidelines for the reporting and conduct of systematic reviews (Moher et al., 2009). We ran a search of the literature in February 2019 covering six databases chosen to span multiple disciplines and formats: Web of Science, PsycINFO, Ovid Medline, the Educational Resources Information Centre (ERIC), Proquest Dissertations and Theses, and ACM Digital Library. The search employed a combination of keywords and subject terms relating concepts of tech devices or social media (e.g., "smartphone," "internet," "social networking site"), adolescents (e.g., "teen," "youth"), and parental monitoring or support (e.g., "parent" or "family" adjacent to "monitoring" or "involvement"). The full list of search terms and databases can be found in Supplement 1. We limited the search to studies that were published from 2008 onwards; were published in English; and were published as peer-reviewed journal articles, dissertations or theses, conference papers or conference proceedings, books, or book chapters. We adopted a time frame of 10 years to encompass the rise of smartphones over the past decade with the goal of measuring parenting of adolescents' use of mobile devices including smartphones, laptops, video games, and other new technologies. The search identified 3,427 publications. After removal of duplicate results, 2,800 unique publications remained to be screened.

\section{Screening of Quantitative Search Results}

We first screened the search results for quantitative survey research, using Rayyan Software (Ouzzani et al., 2016). Abstracts and full texts were screened against several inclusion criteria. First, the analysis in question needed to have employed either original survey research or secondary analysis of a survey data set. Second, the mean age range of adolescents assessed needed to be between 10 and 17 years. Third, parental monitoring of, involvement in, and/or support of adolescent technology use needed to be examined; however, we did not include research focused solely on television viewing. Fourth, the research's focus needed to be on monitoring of adolescent technology behavior, and not on parental use of digital technology to monitor offline behavior (e.g., using GPS tracking on a phone to monitor a child's whereabouts). Finally, the survey items in question needed to have assessed recent behaviors and not, for example, retrospection to the time of adolescence among adults.

All four authors double-blind screened an initial sample of 100 search results for inclusion/exclusion using the above criteria; results were then compared, and discrepancies resolved by discussion. Subsequently, the remaining search results were double-blind screened for inclusion/exclusion by a sub-set of the authors (KM, RG, AO) using the same criteria. Coders agreed on $97 \%$ of publications. Disagreements were resolved through group discussion. The screening process yielded 157 papers for inclusion. Closer scrutiny later revealed that 12 papers did not meet the inclusion criteria (e.g., were focused exclusively on television viewing). Thus, the final sample for analysis comprised 145 papers. The search and screening process are summarized in a PRISMA flow diagram in Figure 1. 

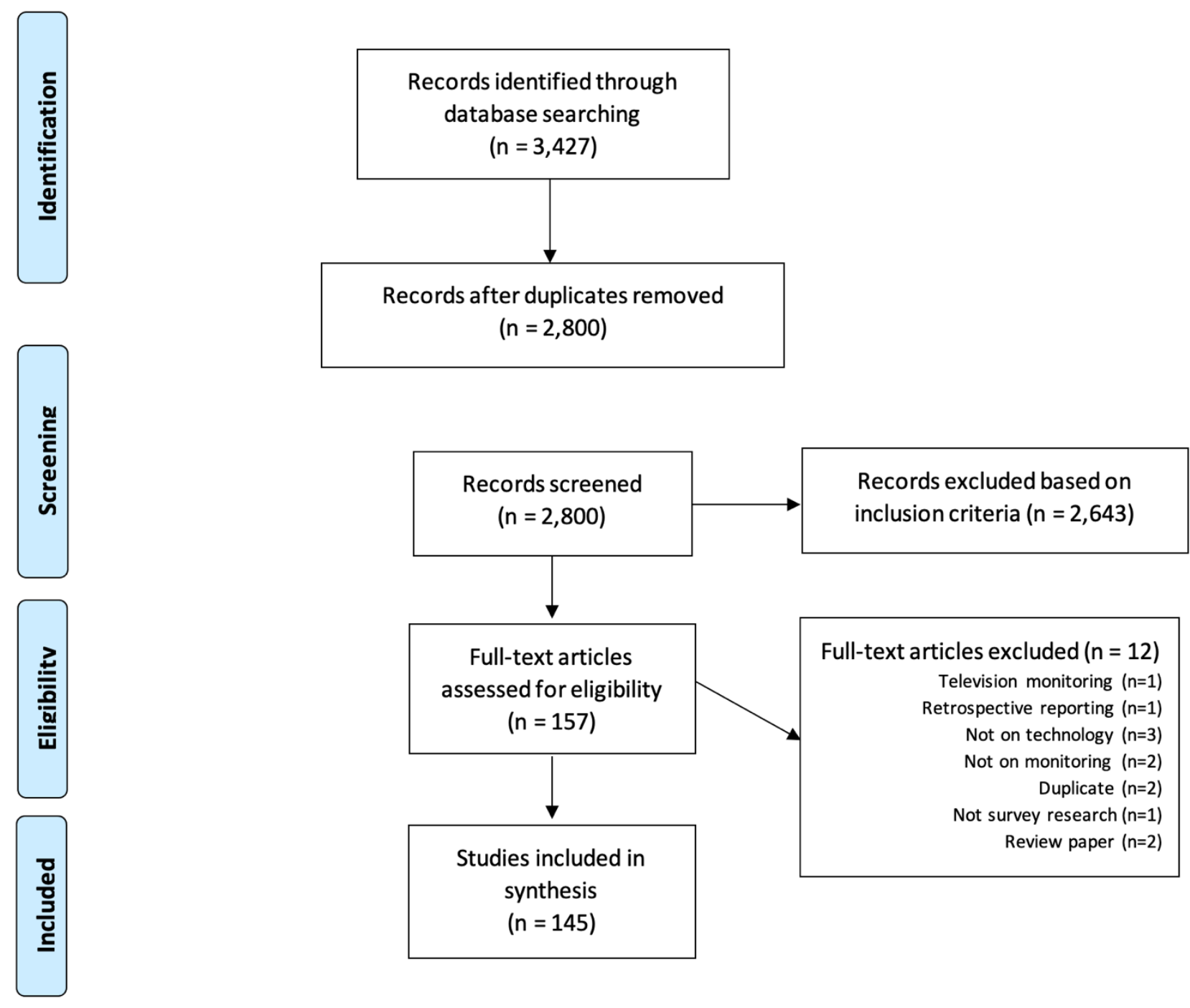

Figure 1. PRISMA flow diagram of the interdisciplinary systematic review of quantitative survey-based research of digital parenting.

\section{Quantitative Data Extraction and Coding}

Our data extraction and coding process for the quantitative survey research was two-pronged. In the first stage, we recorded a host of details about each study (e.g., sample size, country, parent and/or adolescent respondent). In addition, we extracted from each study the quantitative survey items used to measure digital parenting.

In the second stage, we assigned substantive codes to each of the extracted survey items. Two authors (AO and RG) jointly developed a set of ten substantive codes after closely reading all of the extracted items: 1 ) technological encouragement; 2) co-use; 3) hovering; 4) instruction; 5) discussion; 6) crisis intervention; 7) monitoring; 8) filtering; 9) basic rule setting; and 10) content-specific rule setting. Definitions of each code are provided in Table 1. The two authors double-blind coded each survey item using the list of codes, distinguishing between parent and adolescent-reported items. As a measure of inter-rater reliability, the Cohen's Kappa for parent-reported items was $91 \%$, and for adolescent-reported items was $82 \%$. Discrepancies were resolved through discussion. 
Table 1

Table detailing the codes extracted from quantitative survey items by the study team, detailing ten different categories of digital parenting ranging from basic rule setting to monitoring. The table includes the code, its definition and an example taken from the survey items reviewed.

\begin{tabular}{|c|c|c|}
\hline Code & Definition & Example $^{1}$ \\
\hline $\begin{array}{l}\text { Basic rule set- } \\
\text { ting }\end{array}$ & $\begin{array}{l}\text { Specifying general rules for technology use. This includes the } \\
\text { amount of time that can be spent on technology, the place or lo- } \\
\text { cation of access, and the time of day of access. This also in- } \\
\text { cludes basic rules about supervision (e.g., an adolescent needing } \\
\text { to tell their parents when they go online; not allowing an adoles- } \\
\text { cent to go online by themselves). }\end{array}$ & $\begin{array}{l}\text { "I limit the time my child is } \\
\text { allowed on the internet (e.g., } \\
\text { only one hour a day)" }\end{array}$ \\
\hline $\begin{array}{l}\text { Content-spe- } \\
\text { cific rule set- } \\
\text { ting }\end{array}$ & $\begin{array}{l}\text { Specifying rules that limit the adolescent's access to certain } \\
\text { technological platforms (e.g., allowing them to have a social me- } \\
\text { dia profile, allowing access to certain websites or game rooms) } \\
\text { or their access for certain purposes (e.g., to do homework, to } \\
\text { visit specific websites, to chat with strangers). }\end{array}$ & $\begin{array}{l}\text { "I limit the type of websites } \\
\text { my child is allowed to } \\
\text { visit" }\end{array}$ \\
\hline Co-use & $\begin{array}{l}\text { Active participation in the same technological activity concur- } \\
\text { rently (e.g., posting on each other's Facebook profile is not in- } \\
\text { cluded as it is not clear whether this is done concurrently). This } \\
\text { also includes items about the parent actively helping the adoles- } \\
\text { cent succeed in a technological task. }\end{array}$ & $\begin{array}{l}\text { "...do shared activities to- } \\
\text { gether with your child on } \\
\text { the internet" }\end{array}$ \\
\hline $\begin{array}{l}\text { Crisis inter- } \\
\text { vention }\end{array}$ & $\begin{array}{l}\text { Parent helping the adolescent when something goes wrong when } \\
\text { using technology. }\end{array}$ & $\begin{array}{l}\text { "Helped him/her in the past } \\
\text { when something has both- } \\
\text { ered him/her on the inter- } \\
\text { net" }\end{array}$ \\
\hline Discussion & $\begin{array}{l}\text { Bi-directional communication between the parent and adolescent } \\
\text { about technology use. }\end{array}$ & $\begin{array}{l}\text { "I talk with my child about } \\
\text { what he/she does on the in- } \\
\text { ternet" }\end{array}$ \\
\hline $\begin{array}{l}\text { Encourage- } \\
\text { ment }\end{array}$ & $\begin{array}{l}\text { Parents encouraging the adolescent to use/explore technology, } \\
\text { for example to learn new skills or engage in another activity with } \\
\text { a positive outcome. }\end{array}$ & $\begin{array}{l}\text { "Encourage your child to } \\
\text { explore and learn things on } \\
\text { the internet on their own" }\end{array}$ \\
\hline Filtering & $\begin{array}{l}\text { Using technological means to control the adolescent's access to } \\
\text { particular aspects of technologies (e.g., websites or apps) or the } \\
\text { time spent on particular devices. }\end{array}$ & $\begin{array}{l}\text { "Do you use filter software } \\
\text { or other means of blocking } \\
\text { some types of websites?" }\end{array}$ \\
\hline Hovering & $\begin{array}{l}\text { Not being engaged in the same technological activity, but being } \\
\text { in the vicinity of the adolescent engaging in with technology } \\
\text { (e.g., being in the room). References to general supervision with- } \\
\text { out further information about the nature/kind is also classified as } \\
\text { hovering. }\end{array}$ & $\begin{array}{l}\text { "Keep an eye on what's on } \\
\text { the screen while your child } \\
\text { is online" }\end{array}$ \\
\hline Instruction & $\begin{array}{l}\text { Conveying information about technology use from parent to ad- } \\
\text { olescent in an educational manner. }\end{array}$ & $\begin{array}{l}\text { "I show my child how to } \\
\text { surf safely on the internet" }\end{array}$ \\
\hline Monitoring & $\begin{array}{l}\text { Parents using technological and non-technological means to re- } \\
\text { ceive information about what their adolescents are doing online } \\
\text { (e.g., checking the adolescent's Facebook profile or text mes- } \\
\text { sages, installing monitoring software, having access to pass- } \\
\text { words). This does not include knowledge of things like number } \\
\text { of friends on social media, or more general knowledge about } \\
\text { what the adolescent is doing on technologies. The item needs to } \\
\text { reference a parental monitoring behaviour (e.g., checking text } \\
\text { messages). }\end{array}$ & $\begin{array}{l}\text { "Do you check which web- } \\
\text { sites your child visited after } \\
\text { he/she finishes surfing the } \\
\text { internet?" }\end{array}$ \\
\hline
\end{tabular}

${ }^{1}$ Examples in the table are limited to parent items, although similar items were often asked of adolescents themselves. 


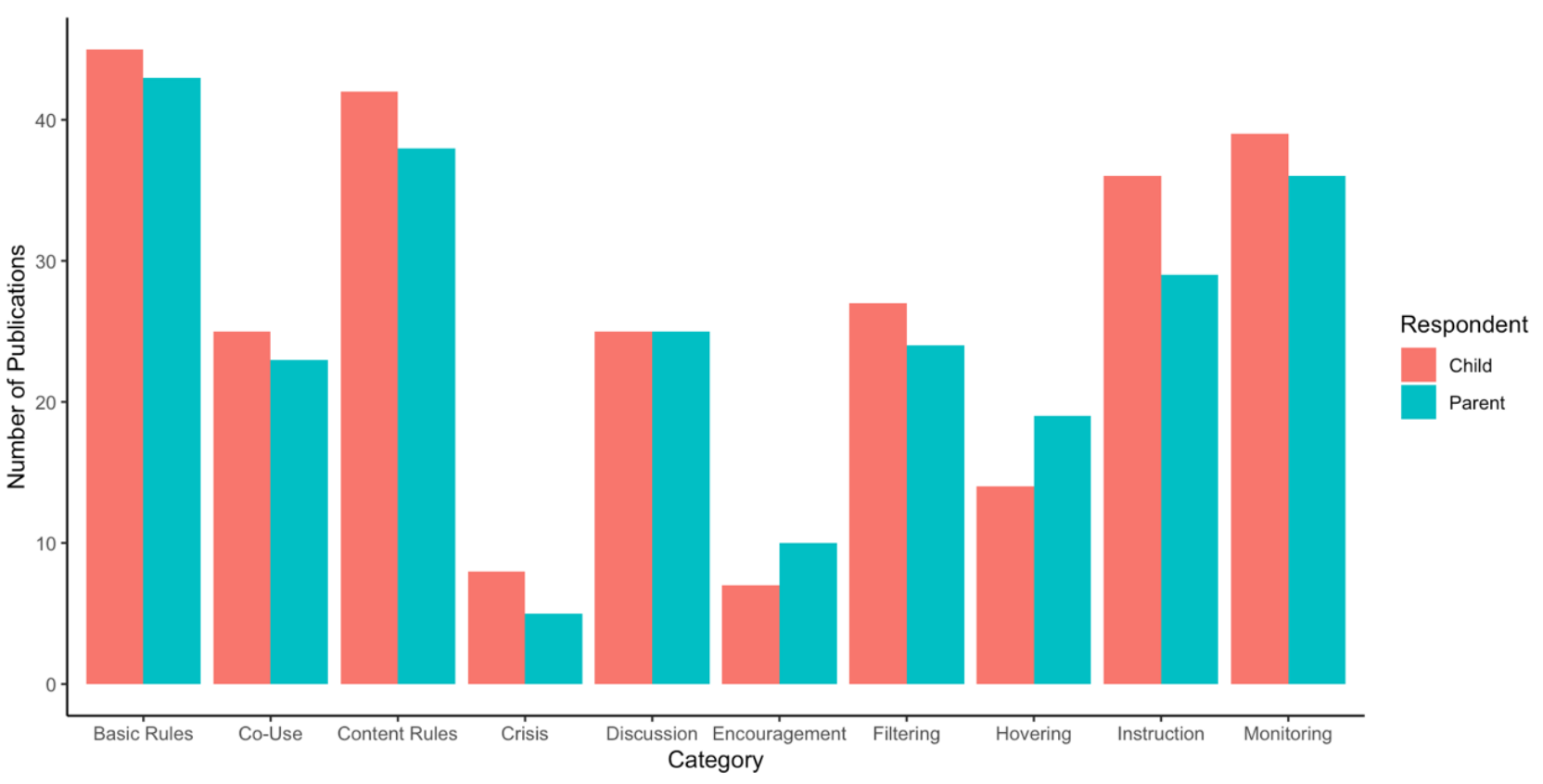

Figure 2. Bar chart of the number of publications and other reviewed outputs that had survey items pertaining to certain categories/codes of digital parenting. The categories include basic rules about when, where and how long technologies can be used ("basic rules);" parents cousing technology with their child ("co-use"); rules about what content or platforms children are allowed to access ("content rules"); helping children if they have a crisis on digital technologies ("crisis"); discussing the use of digital technologies with their child ("discussion"); the encouragement of digital technology use for positive means ("encouragement"); the use of technological aids to block or filter certain types of digital content ("filtering"); remaining in the vicinity of a child on digital devices ("hovering"); instructing children how to use digital technologies and providing children with information ("instruction"); and monitoring children's use of digital technologies through either direct or technological means ("monitoring"). The colors correspond to whether the child (red) or parent (green) was asked the survey item.

Of the 145 papers in the sample, 24 did not contain sufficient detail on the survey items measuring digital parenting to permit coding, and we were not able to procure the items separately; these papers were excluded from the analysis. A further 37 papers provided only examples of relevant survey items and the full set of items was not procurable; only the available sample items were therefore used for coding. Thus, we were able to code the complete set of survey items used for 84 papers, and for 37 papers we coded a partial set.

\section{Results of the Quantitative Review}

The quantitative review highlighted which areas of digital parenting were most often targeted in the interdisciplinary survey-based studies reviewed, and which areas were often overlooked (see Figure 2). Rules about the time, place or length of time digital technologies can be used by adolescents ("basic rules") and also the content they are allowed to consume on these digital technologies ("content rules") were by far the most popular areas of digital parenting to measure, both when asking children and their parents. Further, items about instructing children about how to use their digital technologies ("instruction") and monitoring their use either directly or via technological aids ("monitoring") were popular across studies.

Least popular were items about helping children when they had experienced something distressing online ("crisis") or encouraging their digital technology use for positive means ("encouragement"). Further, other more active and engaged forms of digital parenting were only sometimes asked about in studies, such as jointly surfing the internet or playing video games together ("co-use"), discussing with the child the digital technologies they use and the digital content they experience ("discussion"), and staying near the child to 
keep an eye on technology use ("hovering"). Filters or parental controls that block certain types of content or limit time online ("filtering") were asked about roughly as frequently as the "discussion" theme.

When examining what digital technologies were targeted by the survey items, we also observed a clear skew. Most of the items asked parents and children generally about their use of the "internet" (268 items) or used the word "online" (129 items). Substantially fewer items probed social media use (43 items) or gaming specifically (70 items). Most quantitative measures therefore focused predominantly on general uses of the internet and digital technologies that afford adolescents to go online, and the setting of rules about how they are allowed to use these broad categories of technologies.

When looking more closely at the measures themselves, the largest proportion are focused on restrictions; specifically, the prevention of spending too much time online or of exposure to certain platforms or materials. Some of the most popular items asked parents about time-based restrictions: whether they only allowed their child to use digital technologies at specific days and/or times (e.g., "I only allow my child to surf the internet at specific days and times," "Homework must be completed first") or whether they set limits or enacted rules about their child's amount of time on digital technologies (e.g., "I set limits around the time my teen spends on digital technologies"). Some studies also included items on location-based restrictions (e.g., "I make sure my child uses technology in a public space at home (living room, dining room, etc.)"). Further, many asked about whether, when using digital technologies, there were rules about what the adolescents were allowed to engage in (e.g., "I set specific rules for using smartphones," "I stop my child when he/she visits a less suitable website," "Set rules about interacting with strangers or which websites can be visited").

Less restriction-focused items still largely targeted risk prevention. For example, in the "instruction" category some of the most popular items centered on safety (e.g., "Do your parents suggest to you ways to use the internet safely") or protection (e.g., "Explaining why some websites are good/bad," "Whether a parent ever had a discussion with their adolescent about privacy settings and social media safety"). Moreover, many parental monitoring items tended to focus on independently gathering information about children's activities and social networks, rather than soliciting or encouraging children's self-disclosure (e.g., "tracking his/her Facebook page or checking his/her search history," "check[ing] the contents of your child's cell phone," or even "installing software to...monitor children's online activity").

Fewer survey items considered positive uses of technology, adolescent self-disclosure, or digital skillbuilding (e.g., "Have you ever been told by your parents how to search for information?"). Yet there were some items that did. For example, a relatively small number of studies included items about adolescent selfdisclosure of online activity (e.g., "How often do you discuss what you are doing online with your parents?"). Others asked about encouragement of independent exploration on the internet (e.g., "Encourage your child to explore and learn things on the internet on their own").

\section{Review of Qualitative Studies of Digital Parent- ing}

To identify what aspects of digital parenting have been under-represented or over-emphasized in survey research to date, we complemented our systematic review of the survey literature with a secondary systematic examination of results from qualitative research. This parallel characterization of qualitative accounts allowed us to highlight important gaps and opportunities for psychological research on parenting in the digital age. Thus, a key contribution of our review is not only bridging the multidisciplinary fields of psychology, sociology, communication, and human-computer interaction, but also bridging the methodological divide between the quantitative and qualitative literature within these fields.

\section{Identification of literature and screening of search results}

We made use of the same systematic search results as the quantitative review to survey the qualitative research (2,800 unique items). The four authors screened abstracts and full texts against similar inclusion criteria as for the quantitative studies. However, instead of limiting the search to studies that used survey items, we now screened only for studies that used focus groups, interviews, and/or open-ended responses. As in the quantitative screening, all four authors blindly screened an initial sample of 100 search results to test the inclusion criteria; results were compared, and discrepancies resolved by discussion. Subsequently, the remaining 2,700 search results were each double-blind screened for inclusion/exclusion by all four authors. The screening process yielded 63 potential papers for inclusion. Upon full text review, closer scrutiny revealed that 14 papers did not include appropriate qualitative data (e.g., 


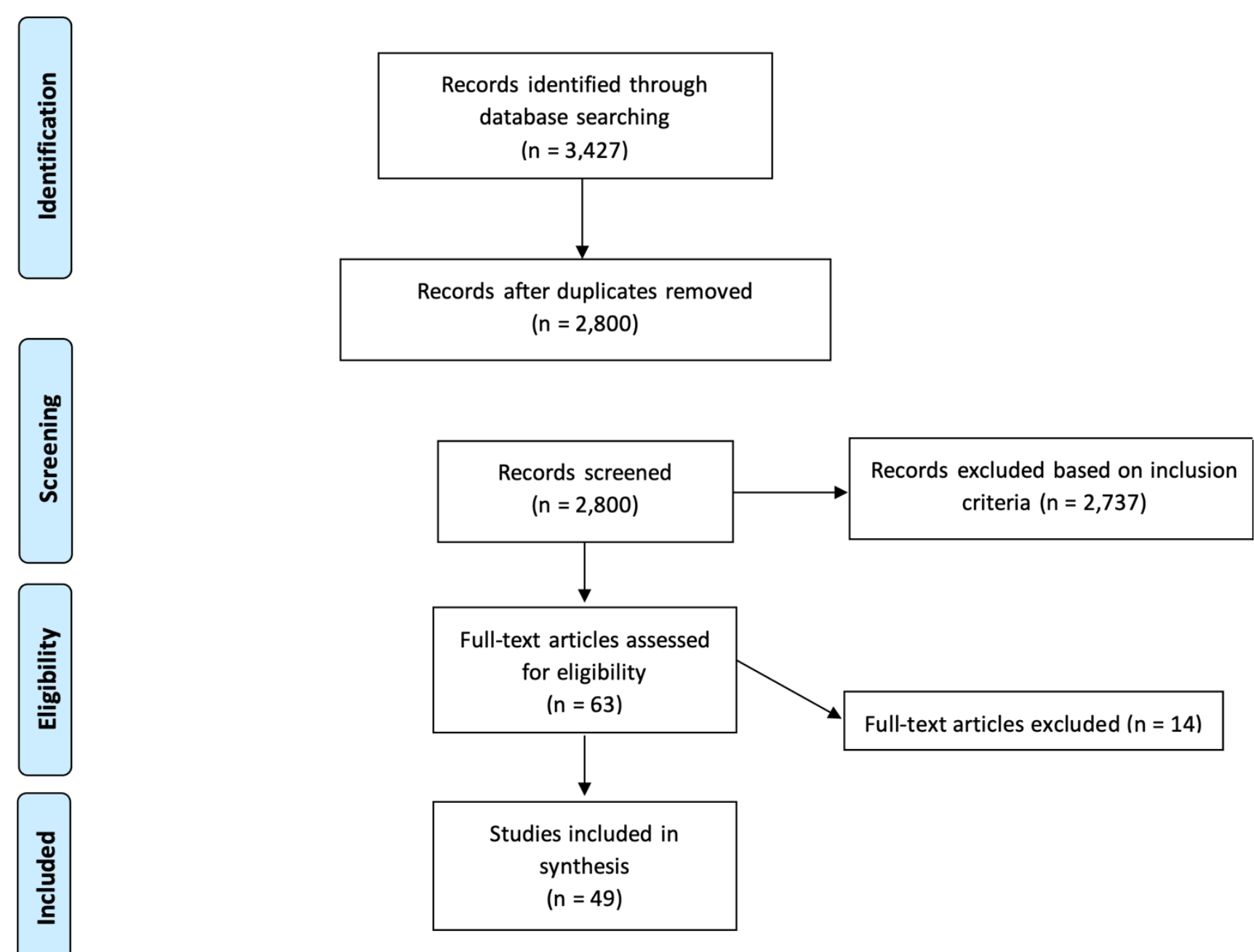

Figure 3. PRISMA flow diagram of the interdisciplinary systematic review of qualitative research of digital parenting.

they reported a mixed method approach but reported interpretable findings only from quantitative results, Alqahtani et al., 2017). Thus, 49 papers comprised the final sample for analysis. The identification and screening process are summarized in a PRISMA flow diagram in Figure 3.

\section{Qualitative Coding}

In the first stage of coding, $\mathrm{KM}$ and PW developed an original coding schema to be used when coding the 49 studies. In a second stage, the schemas were subsequently developed and modified inductively through close readings of each paper. If a paper demonstrated a given theme, an illustrative quote was selected. Thus, for each paper, we applied pertinent codes and extracted a representative quote for each code identified.
The definitions and frequencies of each coded theme are presented in Supplement 2.

\section{Results of the Qualitative Review}

Six broad themes emerged from the review of the qualitative literature: 1) Restriction and Rule Setting, 2) Parental Monitoring, 3) Parental Communication and Support (Mediation), 4) Parent Teen Boundary Negotiation, 5) Social Ecologies of Support, and 6) Appreciation of Technology. We begin below with the concepts that most resembled those included in the survey literature, while noting departures from the focus of surveys throughout. Subsequently, we detail concepts that were absent entirely from the quantitative survey literature, but which we deemed worthy of consideration in future survey research on digital parenting. 


\section{Themes found in both the qualitative and quantita-} tive literature

Restriction and rule setting. In the qualitative literature, Restriction and Rule Setting encapsulated basic house rules such as "There's no taking pictures of yourself and sending it unless it's like you have clothes on, there shouldn't be pictures, nothing like that, sexting, none of that" (Fletcher \& Blair, 2014). Restriction and rule setting also included a variety of methods for restricting technology use, including using technology to lock down features or set time limits, or physically taking away devices during key times. Illustratively, one parent indicated 'during homework, I don't want his phone nearby to distract him. So we had real strict rules last year...he would have to charge it every night like outside of his room because I did not want him looking at it during homework" (Soleski, 2017). Parents also acknowledged access to technology as leverage within the household, used to "reward" adolescents for completion of their chores and responsibilities, or removed as a "punishment" for failure to fulfill obligations, stating: "I will reward them with the cell phone when they are doing the right thing. I think the phone has a lot of power. The parents have more power over their kids than they think, you know? We're holding the money and we're holding the phone." (Soleski, 2017). Indeed, the material support provided to adolescents to purchase technology or pay for monthly fees or upgrades was a common theme in terms of policing adolescents' use and behavior, as this parent goes on to share: "Mom pays for it so Mom gets total access to the phone. Mom also takes it away if she feels it needs to be taken away" (Soleski, 2017). Also touching on the idea that alternative obligations and activities can help set boundaries on technology use, parents described keeping their children busy with an array of non-technology activities (e.g., sports) or hobbies (e.g., music) so that the child would have limited bandwidth for reactional use of technologies. This "time balancing" approach, as explained by one parent meant "always look(ing) for activities, even Saturdays, Sunday, we're always in the street" (Gomez, 2018).

Restriction and rule setting was also carried out by focusing on the quality of peers' behavior and their potential for negative influence. For example, in a departure from what was covered in the quantitative items, restriction sometimes encompassed parents tracking adolescents' peers via technology, not only to monitor them, but also to decide with whom they are allowed to spend time. Parents and adolescents both described peers' unsupervised use of technology or their behavior online as a litmus test for whether adolescents were allowed to spend significant amounts of time with them, stating, for instance " $[\mathrm{I}]$ know when he's at his friend's house, they're online...I've told those mothers how I feel about that" (Mendoza, 2013). Hence, rules and restrictions were also salient parental considerations for judging peers, with parental comments such as "When somebody posts to her Facebook, then I'll go into their profile and I'll start to look at those people. And I look at their photo albums. I see if their parents are in with them. I look at their interests and their schooling or whatever that's on that" (Erikson, 2016).

Parental monitoring. Also prevalent in the qualitative literature, as in the survey items, was the umbrella concept of Parental Monitoring. This included parents actively monitoring adolescents on an ongoing basis by friending them on social media or social media "stalking," so that adolescents were under near-constant supervision in relation to their social network profiles (or at least those profiles known to parents). Given adolescents' need for space and privacy in their development towards independence, not surprisingly adolescents described frustration with this level of scrutiny, with one adolescent commenting "your parents are always checking on you, and if you say something bad, you get in trouble. With me it would happen a lot, like with time, if I posted at midnight, my mom would be like 'You should have been in bed. It's a school night!' (Rickman, 2013). Monitoring also included use of parental control apps or other technologies for surveillance. For example, one parent stated, "I can easily just turn my phone on and check what's going on the laptop. We have them synchronized like that" (Vongkulluksn, 2016).

More commonly, however, Parental Monitoring was characterized as "intermittent." Parents gained access to devices sporadically, either requiring access to devices on demand or secretly gaining access in order to review children's activities. As one adolescent described in relation to her mother, intermittent access was still experienced as invasive, commenting: "She thinks she slick ... so she'll come in and she'll be pretending like she's wiping something off or getting something up and I'll be like okay, and I'll be scrolling down and she'll be like, 'Who is that?' and asking me questions" (Fletcher \& Blair, 2014).

Parental communication and support. Parental Communication and Support (Mediation) was a theme more prevalent in the qualitative literature than in the survey items. This is largely reflected in the roots of 
these qualitative data in communication and media studies fields. The theme was primarily grounded in parents' positive and open communication regarding youths' technology use. For example, one parent likened the online space to a potentially risky area that needs to be scaffolded, saying "You wouldn't take a kid to a pool and say, 'Don't go swimming, you might drown.' You're gonna take them to the pool, and you're gonna teach them ways to be safe around water" (Mendoza, 2013).

Often, parents spoke of giving youth broad guidelines in which to operate, in order to stay actively involved in their child's online life and encourage selfdisclosure. Illustratively, a parent described: "We have open discussions about what types of inappropriate things he might encounter, what to do if he finds these things, how to use the internet safely, and all of the positive things the internet can provide" (Liebeskind, 2013). Likewise, parents encouraged self-disclosure, indicating that warmth and openness in their relationship allowed for adolescents to share emerging issues, stating for instance: "It is important to talk. If they know that they can come to you in case of a problem, I find that important." (Symons, 2017). That said, Parental Communication and Support additionally included what were described as constant calibrations and a perceived need to balance a desire to monitor youth with desires to trust the child and respect their privacy. For instance, one parent noted: "I feel like he's old enough that I have to give him privacy. And I don't want to be breathing down his neck all the time because I don't want to alienate him." (Erickson, 2016).

This theme also involved encouraging and teaching children how to be "decent" individuals via digital citizenship. As one parent pointed out, they taught their child basics of behavior-"How do I communicate with others. That's what it's all about for me. What I don't dare to say in someone's face, I also won't write it down. It's a kind of respect that you need to have I think, also in that medium" (Symonds, 2017). Also reflecting the theoretical grounding of media studies in Bandura's social-learning theory (Clark, 2011), this concept included parenting by example. That is, by parents modelling healthy technology use and limit-setting, children will themselves learn healthy use. For example, one parent commented "We've also had conversations where the kids have told us we're using our devices too much. We appreciate having it pointed out, because you're right. It's not a good example" (Blackwell et al., 2016).

\section{Themes found mainly in the qualitative literature}

Importantly, our parallel qualitative review also allowed us to characterize prevalent themes emerging from interviews with parents and adolescents which are not yet covered within current quantitative survey research on parenting of adolescent technology use. We focus on three broad themes which illustrate deficits in the ways digital parenting has been assessed, including Parent-Teen Boundary Negotiations, Social Ecologies of Support, and Alternate Perspectives on Technology.

Parent-teen boundary negotiations. First, ParentTeen Boundary Negotiations were often described by both parents and adolescents in the qualitative literature. These represent tensions around parental rules and restrictions on technology use, and how these rules and restrictions are constantly re-negotiated and/or maneuvered around. Parents described a regular back and forth over rules, and a concern that strict rules would backfire: "When I try to keep my child within the boundary of rules, he would start to lie" (Rhim, 2016). Adolescents, in turn, expressed frustration with rubbing up against set limits, describing instances of feeling under the microscope, for example "Here's my iPhone, there's you [their parent]. I'm looking at Twitter, you're looking at me on my phone looking at Twitter." (Blackwell et al., 2016). Unsurprisingly, then, adolescents also described workarounds, in which face-value rules (e.g., no texting peers) were circumvented via another technology (e.g., using social media chats). As described by one adolescent, moving platforms can provide a reprieve from constant parental scrutiny: "Twitter is like [pause], when your parents leave the house and you can have a party. And you do and say what you want. But Facebook is like when mom and dad are home. You have to like, watch yourself." (Rhikman, 2013). Boundary tensions, of course, are a normative aspect of the parent-adolescent relationship. Consequently, understanding the ways parents manage these negotiations, as well as the ways adolescents bargain and circumvent around these technology rules and restrictions, could result in important, developmentally-informed dimensions worthy of future research and measurement.

Social ecologies of support. Second, the Social Ecologies of Support concept broadly encompassed attention to adolescents' development within nested contexts, and more specifically spoke to the significance of family members, friends, and school systems in enforc- 
ing and sometimes establishing digital rules. At the inner-most ecology, parents described enlisting extended family to look out for children on social media, as well as the role of older siblings in helping to monitor technology use at home and provide parents with a sense of their sibling's digital identity. This reliance on extended families was especially prevalent among low SES and racial minority individuals. Illustratively, describing the role of siblings among Puerto Rican and Dominican families living in the US, a parent noted, for example, "the big one is always checking, cause like the other one is younger and that, she is more attentive, closer to the little one, because we are in a ladder [laughs] us with the big one and the big one checks what the little one does" (Gomez, 2018). Wider ecologies also included the role of schools in setting restrictions on youths' access to certain sites, but also the difficulties that ensue when schools' mandates of technology use run counter to parents' technology limits or approaches. For instance, one parent shared "[one] worry of [her son] being online is that the schools aren't necessarily training kids the way I'm training my kids at home." (Mendoza, 2013). During the COVID-19 pandemic, such tensions between parental restrictions and the necessities of technology for school were undoubtedly amplified, and quantifying these tensions within ongoing research will be important.

Appreciation of technology. Finally, the Appreciation of Technology concept largely encompassed parents' understanding of technology's positive potential with respect to social skill building and as a future gateway for career opportunities. For instance, parents described promoting their offsprings' technology use to encourage sociability and communication skills. Parents acknowledged, "this is how they communicate with each other, and I need to get on board and catch up" (Ebersole, 2012). Technology was also described as a pathway to future success. Here, technology was seen largely as an opportunity, for instance "an outletas he (the child), as he gets interested in writing, or in design, or in photography, or whatever it is. It will give you a kind of gallery, a place to exhibit" (Mendoza, 2016). By the same token, lack of access to technology was sometimes described as a looming disadvantage among those families with less access, and as a result, a disparity in being able to provide entryways to skills online which might assist with future career prospects. Adolescents likewise described challenges in printing homework, working on digital assignments from libraries, and other relative disadvantages. Even within class- rooms, this posed a challenge as described by one adolescent: "my theology teacher was like, okay, take your phones out, and we did a live Quizlet, and it was about to pick the topic of our project, so everyone went in their phones, signed in, whatever and they picked...Yeah, so, that means I had to tell the teacher I can't get in" (Gomez, 2018). Considering the role of technology for future prospects and how this manifests differently across diverse family circumstances will be critical for future research.

\section{Discussion}

Concerns about new digital technologies and their potential harm for children have been the subject of considerable societal debate (George \& Odgers, 2015; Hawkes, 2019). Amidst mixed findings regarding the impact of technology use on adolescents' wellbeing (Orben \& Przybylski, 2019a; Twenge et al., 2018), parents are left on their own to balance the competing demands of addressing safety concerns and fostering adolescents' autonomy. To address the challenges of modern parenting, researchers have been seeking new ways of measuring digital parenting. These efforts have largely been ad-hoc, however, and have often involved only small changes in measures developed for television and early media, rather than reconceptualizing digital parenting from a holistic, multi-disciplinary framework that accounts for the particularities of the current technology landscape. The current study's rigorous stock-taking through two interdisciplinary systematic reviews allowed us to gain a comprehensive overview of both current quantitative measurement and of direct qualitative accounts of adolescents and their parents. Merging insights from both quantitative and qualitative literatures allowed us to depict the realities of digital parenting and identify key gaps in how digital parenting strategies have been operationalized to date.

In our review, both the quantitative and qualitative literatures described parental challenges and, in turn, a gamut of approaches to providing youth with appropriate monitoring and support within the changing technology landscape of the post-digital age. The qualitative literature, however, highlighted additional areas of needed focus within future measures. Focus groups and interviews reflected adolescents' need for autonomy, heterogeneity in family's ecological systems for support and monitoring, and the many positive affordances that technology is known to provide adolescents, particularly for families living in settings of disadvantage. Figure 4 summarizes points of juncture and disjuncture between the digital parenting themes identified in the 


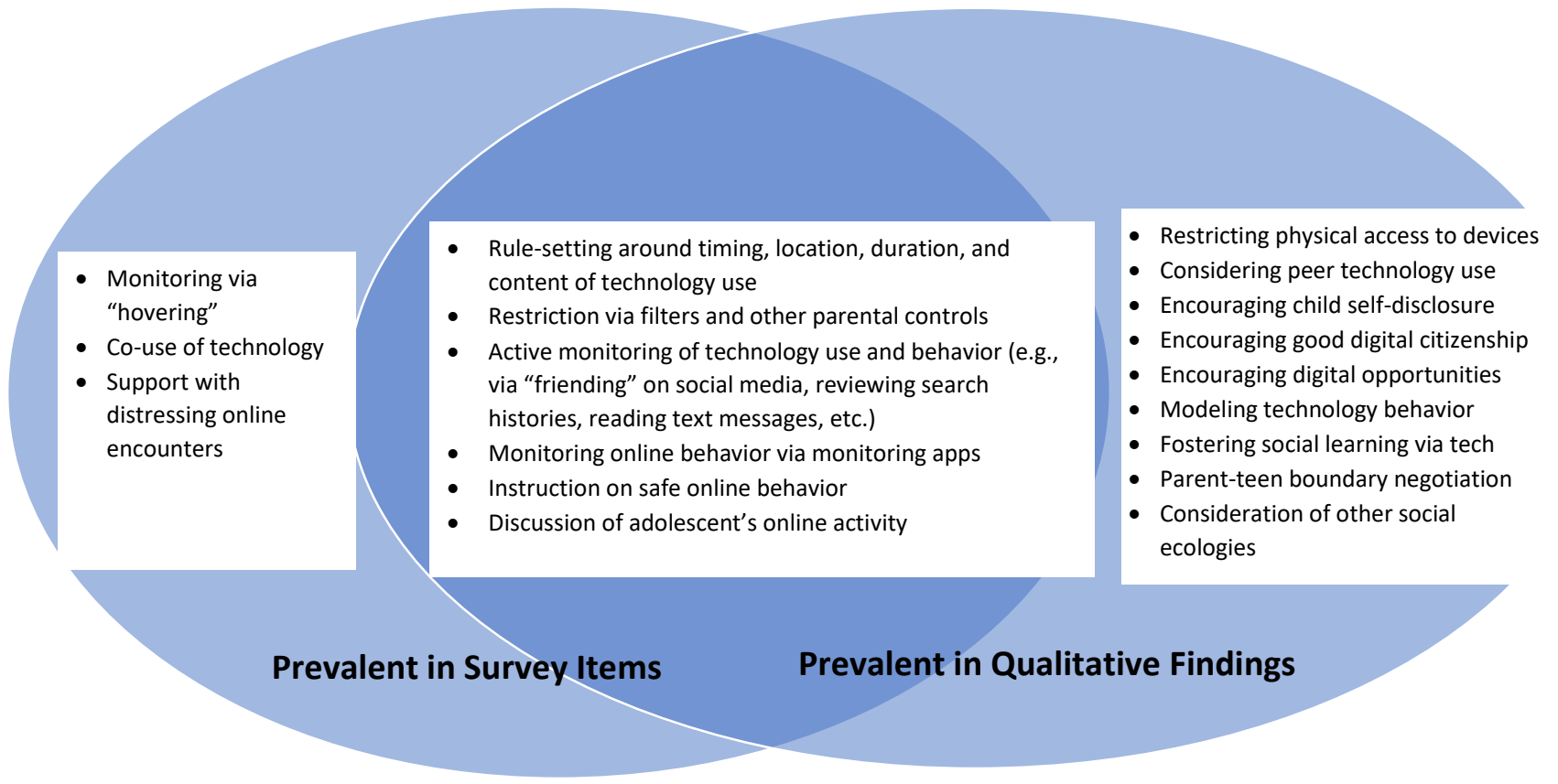

Figure 4. Venn diagram showing concepts prevalent primarily in survey items (left), prevalent primarily in qualitative findings (right), and prevalent in both (middle).

review of survey items and those emerging from the review of qualitative research. As described, many concepts appeared in both literatures, but a small sub-set appeared almost exclusively in the quantitative literature (and hence indicate potential over-emphasis in current measurement), and a non-trivial number of concepts appeared almost exclusively in the qualitative literature (and hence may be currently neglected in current quantitative measurement).

\section{Restriction and risk}

As characterized in Figure 4 clear overlaps between the quantitative survey and qualitative literatures centered especially around themes related to restriction and risk reduction: both literatures have emphasized restriction via rule-setting (in relation to the timing, location, duration, and content of technology use) as well as restriction via filters or other technology-based controls.

Nonetheless, the qualitative literature provides additional nuance about restriction that should be incorporated into future quantitative work. In particular, two additional means of restriction emerged from the qualitative synthesis: 1) restriction through physical removal of the child's device, which is most feasible with mobile phones and tablets that can, for example, be placed in drawers; and 2) restriction via distraction or "time balancing," for example keeping children busy with extracurricular activities and hobbies that do not involve digital technologies so that they lack time for recreational technology use. It is worth noting that while removing devices is a readily available strategy for restricting mobile technologies, it is also the case that doing so may effectively cut off adolescents' social support network, which could have its own negative consequences (e.g., Leung, 2006). By contrast, time balancing approaches, also widely endorsed by parents, can arguably facilitate adolescents' exposure to novel contexts and complementary opportunities for identity development and skill building (Modecki et al., 2018; Vernon, 2019). As a result, such pro-active time balancing techniques work to both limit technology time and help meet adolescents' developmental mandate for exploration and autonomy (Larson et al., 2002). That said, the differences in effectiveness of these two par- 
enting strategies, and their associated impacts on adolescents' wellbeing, remain unknown and presents an important area for future research.

A final perspective on restriction that was only present within the qualitative literature was how parents make use of information on their children's peers' use of technologies to adjust their rulemaking. For example, a parent might use information seen on a friend's social media profile or their family's rules with respect to digital technology use to decide whether to permit a child to spend time at their house. Thus, rule setting extends beyond the immediate family bubble and includes oversight of more than just the child's use, indicating it is a truly multidimensional behavior.

\section{Monitoring}

Another area in which the quantitative survey research, and to a lesser extent the qualitative literature, often fell short was in its unidimensional conceptualization of parental monitoring, focusing almost exclusively on control-based parenting strategies. Even though developmental research shows very clearly that developing a warm and trusting parent-child relationship and providing youth with autonomy-support leads to better knowledge regarding adolescents' activities (Crouter et al., 2005; Vieno et al., 2009), nearly all measures focused on parental control and independent sourcing of adolescents' information. That is, survey items focused on the varied ways parents worked to independently gather information on adolescents' uses of digital technologies: these included "friending" children on social media to track their posts, checking search histories, examining text messages and call logs, and (less commonly) using software to continually monitor online behavior. Relatively few items measured how parents might encourage self-disclosure directly from their children. This opposes decades of research pointing to the benefits of positive relationship strategies for promoting adolescent safety (Kerr \& Stattin, 2000; Tokić \& Pećnik, 2011) and showing that adolescents' independent self-disclosure is most effective at facilitating parental knowledge of adolescents' whereabouts, activities, and wellbeing (Blodgett Salafia, et al., 2009). As a result, there is significant potential for re-conceptualizations of digital parenting that incorporate basic tenets of parenting which preceded the rise of digital technologies, to ensure adequate representation of positive parenting strategies.

\section{Positive Uses}

An emphasis on risk prevention prevailed in the survey research even among items that were less restriction-focused. For example, survey items considering instruction and support often focused on whether parents teach their children to use the Internet safely or whether they support them when they encounter something distressing online (such as bullying). This risk paradigm was reflected much less frequently in the qualitative accounts; parents within focus groups and interviews often focused on benefits of technology. Positive themes that emerged specifically in the qualitative review included discussions of good digital citizenship, identification and encouragement of digital opportunities, and parent role modelling of positive technology use.

The global idea of "being a good person" and how this translates to the online space was described by parents in focus groups and interviews as an underlying tenet which they applied across their interactions with teens. This goal reflects the primary responsibility of parents of adolescents, to assist with a transition to independent young adulthood, having inculcated youth with a prosocial identity and value system (Allen et al., 1996; Smetana \& Asquith, 1994). One could argue that the goal of good digital citizenship reflects post-digital parenting, where adolescents' values, character, and identity are as much reflected online as offline.

Also critical for post-digital parenting is the recognition of prospects provided by new technologies, and accordingly, identification and encouragement of digital opportunities for adolescents. Parents discerned prospects for professional skills and career pathways using digital technologies when interviewed, as well as potential for academic and social learning in a world where virtual learning and communication are increasingly the norm. Yet there was minimal evidence of such possibilities in survey parenting measures. Forwardfacing future digital parenting studies should weave in positive expectations associated with technology, such as enhanced educational opportunities and a wider breadth of career possibilities, in order to accurately reflect parental perspectives and goals.

\section{Outdated items}

There were several areas where a lack of qualitative evidence highlighted ideas that are not as relevant to the current digital environment as they may have been in the past. For example, "hovering" emerged much less frequently within qualitative accounts than in quantitative research. This suggests that such a parenting strategy may be less feasible or useful 
in the era of personal mobile devices. The common inclusion of hovering items within surveys likely hearkens back to measures based on non-mobile and largescreened technologies such as desktop computers or televisions, which could be monitored from across a room. Given that smartphones and tablets (handheld devices with much smaller screens) are increasingly prevalent, quantitative measurement is arguably ripe for an update.

A further example is parent-child social co-use of technology, a pillar of Valkenburg et al.'s (1999) seminal parental mediation strategies for television viewing. This concept appeared in a non-trivial share of surveys (e.g., shared time surfing the internet or playing video games), yet was relatively absent in the qualitative findings. This suggests that co-use, like "hovering," may be a less relevant digital parenting strategy today, in the age of personal digital devices. While couse may still be an appropriate parenting strategy for technologies such as television and video games, the premise of sharing time together to enhance adolescents' digital experiences on personal digital devices is less clear cut. That said, co-use need not be entirely lost or irrelevant today; at its core, this concept reflects an effort to grow and maintain a positive relationship with adolescents. Its benefits traditionally rested in spending time together and being present positively in adolescents' lives is undoubtedly still important for parenting in the age of the smartphone.

\section{The Way Forward}

Parenting adolescents has long been a complex task, balancing adolescents' need for independence and exploration with appropriate scaffolding and safeguards as they move towards young adulthood. Current research investigating parenting in the digital age has largely focused on the latter, reinforcing a danger-focused lens that emphasizes avoidance of technologyrelated risks. In their original media parenting scales, Valkenburg and Easton (1999; 2006), among other authors, also encouraged measurement of opportunities and positive uses that media enabled, but these have largely receded into the background of the current scientific landscape. This "spotlighting" on risk not only limits scholarly dialogue on affordances and benefits, but also reduces a multidimensional and complex set of parenting behaviors into a single dimension which poorly captures the realities of digital parenting. Hence, not only are we provided with a one-sided (negative) take on digital parenting, but the complex interactions between communicating trust and providing digital opportunities and support to adolescents, alongside restrictions and monitoring to avoid harm, are not usefully reflected.

Further adding to the complexity of digital parenting is the nature of parent-adolescent relationships, which are characterized by bidirectional influence and two-way communication (including adolescent selfdisclosure) (Smetana, et al., 2005). Survey items, however, often assume uni-directionality from parents to teens. Moreover, adolescents' behavioral responses to parent rule-setting are rarely considered, such as technological workarounds (e.g., moving to social media chat when texting privileges are removed and keeping alternative social media profiles secret from parents). Yet, these behaviors tell us as much about the effectiveness of digital parenting strategies as they do about parental knowledge. Likewise, adolescent development necessarily brings with it some degree of parent-youth conflict, as both teens and parents negotiate a level of separation (Allen et al., 1996). Boundary conflicts in which parents set technology rules and recalibrate these based on adolescents' pushback or negotiation are reflective of this normative development and need to be mirrored within the fields' measurement.

Amongst the most striking area of neglect within digital parenting scholarship has been the failure to illustrate and address the different demands made of parents across heterogenous contexts (Huang et al., 2018; Modecki et al., 2020). As a result, the most pressing call to action for digital parent scholars is the need to account for differences in digital parenting norms, values, and behaviors based on socio-economic status and race/ethnicity. For example, parents living in lower-income settings made clear in their interviews and focus group accounts that technology can be a safeguard, keeping adolescents connected and entertained indoors when neighborhoods are unsafe (Gomez, 2017). In addition, parents and adolescents both considered technology as a pathway to privilege, because adolescents will need digital skills to engage in a modern professional landscape. As such, more-not less-technology engagement may be part of many parental agendas.

Finally, and related to family diversity, is the need to consider the role of grandparents, siblings, and other extended family members within the caregiving orb. This theme emerged most frequently in interviews with non-White parents and/or lower socioeconomic status parents, but almost certainly applies to a broad range of families. Indeed, parents often rely on a network of individuals - whether family, friends, and/or schools - to monitor and support their adolescents online. Parents 
may sometimes use such individuals as proxies, and the ways that extended networks maintain knowledge of adolescents' outward facing identity and behavior is a compelling question worthy of future investigation.

\section{Conclusion}

Parental concerns about adolescents' use of technology have been likened to generational concerns that have plagued parents across time, from telephones to television to video games (Wartella \& Jennings, 2000). When it comes to mobile digital technologies, these concerns are only amplified, given their personal use and immersive nature (Orben, 2020b). But underpinning such worries is the eternal parental tension between protecting adolescents' safety and nurturing their autonomy. Alongside potential risks of technologies such as smartphones exist real affordances for connection, creative exploration, and academic and career opportunities (Modecki et al., 2021a). While past digital parenting measurement has zeroed-in on parental concerns regarding looming risks, largely neglected has been the nature of adolescent development and the many advantages new technologies provide.

In order to better characterize the state of the field and provide direction for future measurement and study, we undertook two interdisciplinary systematic reviews of digital parenting measurement and experience. Examining both quantitative and qualitative literatures, this approach provided a needed bridge to narrow the chasm between understanding how parenting of adolescents appears "on the ground," and how researchers have characterized parental monitoring and support in the post-digital age. Decades of developmental research has shown that parents can meet youths' developmental needs by providing safeguards while simultaneously allowing for a process of emotional and physical separation (Allen et al., 1996; Roth et al., 2009). The online space is no different, and our interpretation of the research landscape highlights important oversights and opportunities for novel, pressing psychological research on digital parenting.

\section{References}

Allcott, H., Braghieri, L., Eichmeyer, S., \& Gentzkow, M. (2020). The welfare effects of social media. American Economic Review, 110(3), 629-76.

Allen, J. P., Hauser, S. T., O'Connor, T. G., Bell, K. L., \& Eickholt, C. (1996). The connection of observed hostile family conflict to adolescents' developing autonomy and relatedness with parents. Development and Psychopathology, 8(2), 425-442
Allison, S., Bauermeister, J. A., Bull, S., Lightfoot, M., Mustanski, B., Shegog, R., \& Levine, D. (2012). The intersection of youth, technology, and new media with sexual health: moving the research agenda forward. Journal of Adolescent Health, 51(3), 207-212.

Alqahtani, N., Furnell, S., Atkinson, S., \& Stengel, I. (2017, September). Internet risks for children: Parents' perceptions and attitudes: An investigative study of the Saudi Context. In 2017 Internet Technologies and Applications (ITA) (pp. 98-103). IEEE.

Anderson, M., \& Jiang, J. (2018). Teens, social media \& technology 2018. Pew Research Center, 31, 1673-1689.

Anderson, M., \& Perrin, A. (2018). Nearly one-in-five teens can't always finish their homework because of the digital divide. Pew Research Center, 26.

Auxier, B., Anderson, M., Perrin, A., \& Turner, E. (2020, August 8). Parenting children in the age of screens. Pew Research Center. Retrieved from https://www.pewresearch.org/internet/2020/07/28/parenting-children-inthe-age-of-screens/

Badillo-Urquiola, K., Page, X., and Wisniewski, P. (2019) Risk vs. Restriction: The tension between providing a sense of normalcy and keeping foster teens safe online. In Proceedings of the 2019 CHI Conference on Human Factors in Computing Systems, 114. CHI '19. https://doi.org/10.1145/3290605.3300497.

Bandura, A. (1978). Social learning theory of aggression. Journal of Communication, 28(3), 12-29.

Bell, V., Bishop, D. V., \& Przybylski, A. K. (2015). The debate over digital technology and young people. BMJ, 351 .

Benjamin, R. (2019). Assessing risk, automating racism. Science, 366(6464), 421-422.

Beyens, I., Pouwels, J. L., van Driel, I. I., Keijsers, L., \& Valkenburg, P. M. (2020). The effect of social media on well-being differs from adolescent to adolescent. Scientific Reports, 10(1), 111.

Blackwell, L., Gardiner, E., \& Schoenebeck, S. (2016, February). Managing expectations: Technology tensions among parents and teens. In Proceedings of the 19th ACM Conference on Computer-Supported Cooperative Work \& Social Computing (pp. 1390-1401).

Blodgett Salafia, E. H., Gondoli, D. M., \& Grundy, A. M. (2009). The Longitudinal Interplay of Maternal Warmth and Adolescents' Self-Disclosure in Predicting Maternal Knowledge. Journal of Research on Adolescence, 19(4), 654-668.

Bornstein, M. H., Jager, J., \& Putnick, D. L. (2013). Sampling in developmental science: Situations, shortcomings, solutions, and standards. Developmental Review, 33(4), 357-370.

Chassiakos, Y. L. R., Radesky, J., Christakis, D., Moreno, M. A., $\&$ Cross, C. (2016). Children and adolescents and digital media. Pediatrics, 138(5).

Chen, L., \& Shi, J. (2019). Reducing harm from media: A metaanalysis of parental mediation. Journalism \& Mass Communication Quarterly, 96(1), 173-193. https://doi.org/10.1177/1077699018754908

Clark, L. S. (2011). Parental mediation theory for the digital age. Communication Theory, 21(4), 323-343.

Collins, W. A., Laursen, B., Mortensen, N., Luebker, C., \& Ferreira, M. (1997). Conflict processes and transitions in parent and peer relationships: Implications for autonomy and regulation. Journal of Adolescent Research, 12(2), 178-198.

Courtois, C., \& Nelissen, S. (2018). Family Television Viewing and Its Alternatives: Associations with Closeness within and between Generations. Journal of Broadcasting \& Electronic Media, 62(4), 673-691. 
Crouter, A. C., Bumpus, M. F., Davis, K. D., \& McHale, S. M. (2005). How do parents learn about adolescents' experiences? Implications for parental knowledge and adolescent risky behavior. Child Development, 76(4), 869-882.

Deci, E. L., \& Ryan, R. M. (2000). The" what" and" why" of goal pursuits: Human needs and the self-determination of behavior. Psychological Inquiry, 11(4), 227-268.

Dienlin, T., \& Johannes, N. (2020). The impact of digital technology use on adolescent well-being. Dialogues in Clinical Neuroscience, 22(2), 135.

Eastin, M. S., Greenberg, B. S., \& Hofschire, L. (2006). Parenting the Internet. Journal of Communication, 56(3), 486-504. https://doi.org/10.1111/j.1460-2466.2006.00297.x

Ebersole, D. S. (2012). "There is no manual to this mess": Parentadolescent communication patterns, privacy management, and talks about substance use. The Pennsylvania State University.

Ellison, T. L., \& Solomon, M. (2019). Counter-storytelling vs. deficit thinking around African American children and families, digital literacies, race, and the digital divide. Research in the Teaching of English, 53(3), 223-244.

Erickson, L., Wisniewski, P., Xu, H., Carroll, J.M., Rosson, M.B. and Perkins, D.F. (2016) The boundaries between: Parental involvement in a teen's online world. Journal of the Association for Information Science and Technology, 67(6), 1384-1403. https://doi.org/10.1002/asi.23450.

Flake, J. K., Pek, J., \& Hehman, E. (2017). Construct validation in social and personality research: Current practice and recommendations. Social Psychological and Personality Science, 8(4), 370-378.

Fletcher, A. C., \& Blair, B. L. (2016). Implications of the family expert role for parental rules regarding adolescent use of social technologies. New Media \& Society, 18(2), 239-256.

Fletcher, A. C., Steinberg, L., \& Williams-Wheeler, M. (2004). Parental influences on adolescent problem behavior: Revisiting Stattin and Kerr. Child Development, 75(3), 781-796.

Garg, R., \& Sengupta, S. (2020). He Is Just Like Me: A Study of the Long-Term Use of Smart Speakers by Parents and Children. Proceedings of the ACM on Interactive, Mobile, Wearable and Ubiquitous Technologies, 4(1), 11:1-11:24. https://doi.org/10.1145/3381002

George, M. J., \& Odgers, C. L. (2015). Seven fears and the science of how mobile technologies may be influencing adolescents in the digital age. Perspectives on Psychological Science, 10(6), 832-851.

Gomez, S. E. (2017). Information practices relative to parental mediation and the family context among Puerto Rican and Dominican teens. Rutgers The State University of New Jersey-New Brunswick.

Hamilton, J. L., Nesi, J., \& Choukas-Bradley, S. (2020). Teens and social media during the COVID-19 pandemic: Staying socially connected while physically distant [Preprint]. PsyArXiv. https://doi.org/10.31234/osf.io/5stx4

Hamza, C. A., \& Willoughby, T. (2011). Perceived parental monitoring, adolescent disclosure, and adolescent depressive symptoms: A longitudinal examination. Journal of Youth and Adolescence, 40(7), 902-915.

Hankerson, D., Marshall, A. R., Booker, J., El Mimouni, H., Walker, I., \& Rode, J. A. (2016, May). Does technology have race? In Proceedings of the $2016 \mathrm{CHI}$ Conference Extended Abstracts on Human Factors in Computing Systems (pp. 473-486).

Harpin, S., Davis, J., Low, H., and Gilroy, C. (2016) Mobile phone and social media use of homeless youth in Denver, Colorado, Journal of Community Health Nursing, 33:2, 90-97, DOI: $\underline{10.1080 / 07370016.2016 .1159440}$
Hawkes, N. (2019). CMO report is unable to shed light on impact of screen time and social media on children's health. The BMJ, 364, Article 1643. https://doi.org/10.1136/bmj.1643

Heffer, T., Good, M., Daly, O., MacDonell, E., \& Willoughby, T. (2019). The longitudinal association between social-media use and depressive symptoms among adolescents and young adults: An empirical reply to Twenge et al.(2018). Clinical Psychological Science, 7(3), 462-470.

Heron, K. E., \& Smyth, J. M. (2010). Ecological momentary interventions: incorporating mobile technology into psychosocial and health behaviour treatments. British Journal of Health Psychology, 15(1), 1-39.

House of Commons Science and Technology Select Committee.(2019). Impact of social media and screen-use on youngpeople's health (pp. 1-92). London, England: House of Commons. Retrieved from https://publications.parliament.uk/pa/cm201719/cmselect/cmsctech/822/822.pdf

Huang, G., Li, X., Chen, W., \& Straubhaar, J. D. (2018). Fall-behind parents? The influential factors on digital parenting self-efficacy in disadvantaged communities. American Behavioral Scientist, 62(9), 1186-1206.

Hunter, S. B., Barber, B. K., Olsen, J. A., McNeely, C. A., \& Bose, K. (2011). Adolescents' self-disclosure to parents across cultures: Who discloses and why. Journal of Adolescent Research, 26(4), 447-478.

Hwang, Y., Choi, I., Yum, J. Y., \& Jeong, S. H. (2017). Parental Mediation Regarding Children's Smartphone Use: Role of Protection Motivation and Parenting Style. Cyberpsychology, Behavior and Social Networking, 20(6), 362-368.

Jago, R., Edwards, M. J., Urbanski, C. R., \& Sebire, S. J. (2013). General and specific approaches to media parenting: A systematic review of current measures, associations with screen-viewing, and measurement implications. Childhood Obesity, 9 Suppl, S51-72. MEDLINE. https://doi.org/10.1089/chi.2013.0031

Jandrić, P., Knox, J., Besley, T., Ryberg, T., Suoranta, J., \& Hayes, S. (2018). Postdigital science and education.

Jensen, M., George, M. J., Russell, M. R., \& Odgers, C. L. (2019). Young adolescents' digital technology use and mental health symptoms: Little evidence of longitudinal

or daily linkages. Clinical Psychological Science, 7(6), 1416-1433. https://doi.org/10.1177/2167702619859336

Jiow, H. J., Lim, S. S., \& Lin, J. (2017). Level up! Refreshing parental mediation theory for our digital media landscape. Communication Theory, 27(3), 309-328.

Jones, L. M., \& Mitchell, K. J. (2016). Defining and measuring youth digital citizenship. New Media \& Society, 18(9), 20632079.

Jones, L. M., Mitchell, K. J., \& Finkelhor, D. (2013). Online harassment in context: Trends from three youth internet safety surveys (2000, 2005, 2010). Psychology of Violence, 3(1), 53.

Kardefelt-Winther, D. (2014). A conceptual and methodological critique of internet addiction research: Towards a model of compensatory internet use. Computers in Human Behavior, 31, 351354.

Kerr, M., \& Stattin, H. (2000). What parents know, how they know it, and several forms of adolescent adjustment: further support for a reinterpretation of monitoring. Developmental Psychology, $36(3), 366$.

Klein, R. (2018, February 7). Limiting your child's fire time: A guide for concerned paleolithic parents. The New Yorker. https:/www.newyorker.com/humor/daily-shouts/limiting-yourchilds-fire-time-a-guide-for-concerned-paleolithic-parents? 
Koning, I. M., Peeters, M., Finkenauer, C., \& van den Eijnden, R. (2018). Bidirectional effects of Internet-specific parenting practices and compulsive social media and Internet game use. Journal of Behavioral Addictions, 7(3), 624-632.

Kreski, N., Platt, J., Rutherford, C., Olfson, M., Odgers, C., Schulenberg, J., \& Keyes, K. M. (2021). Social media use and depressive symptoms among United States adolescents. Journal of $\mathrm{Ad}$ olescent Health, 68(3), P572-P579. https://doi.org/10.1016/j.jadohealth.2020.07.006

Lam, C. B., McHale, S. M., \& Crouter, A. C. (2014). Time with peers from middle childhood to late adolescence: Developmental course and adjustment correlates. Child Development, 85(4), 1677-1693.

Lanette, S., Chua, P. K., Hayes, G., \& Mazmanian, M. (2018). How much is' too much'? The role of a smartphone addiction narrative in individuals' experience of use. Proceedings of the ACM on Human-Computer Interaction, 2(CSCW), 1-22.

Larson, R., \& Richards, M. H. (1991). Daily companionship in late childhood and early adolescence: Changing developmental contexts. Child Development, 62(2), 284-300.

Larson, R. W., Wilson, S., Brown, B. B., Furstenberg, Jr, F. F., \& Verma, S. (2002). Changes in adolescents' interpersonal experiences: Are they being prepared for adult relationships in the twenty-first century? Journal of Research on Adolescence, 12(1), 31-68.

Lauricella, A. R., Cingel, D. P., Beaudoin-Ryan, L., Robb, M. B., Saphir, M., \& Wartella, E. A. (2016). The Common Sense census: Plugged-in parents of tweens and teens. San Francisco, CA: Common Sense Media.

Law, D. M., Shapka, J. D., \& Olson, B. F. (2010). To control or not to control? Parenting behaviours and adolescent online aggression. Computers in Human Behavior, 26(6), 1651-1656.

Leung, L. (2006). Stressful life events, motives for Internet use, and social support among digital kids. CyberPsychology \& Behavior, 10(2), 204-214.

Liebeskind, K. M. (2013). Parental mediation from Looney Tunes to Angry Birds: Examining how parents are dealing with the content-specific issues of old media and the unique challenges of new media. University of Pennsylvania.

Livingstone, S., Blum-Ross, A., Pavlick, J., \& Ólafsson, K. (2018). In the digital home, how do parents support their children and who supports them? Parenting for a Digital Future, Survey Report 1 .

Livingstone, S., Olafsson, K., Helsper, E. J., Lupianez-Villanueva, F., Veltri, G. A., \& Folkvord, F. (2017). Maximizing opportunities and minimizing risks for children online: The role of digital skills in emerging strategies of parental mediation. Journal of Communication, 67(1), 82-105.

London, R. A., Pastor Jr, M., Servon, L. J., Rosner, R., \& Wallace, A. (2010). The role of community technology centers in promoting youth development. Youth \& Society, 42(2), 199-228.

McClure, E. R., Chentsova-Dutton, Y. E., Holochwost, S. J., Parrott, W. G., \& Barr, R. (2018). Look at that! Video chat and joint visual attention development among babies and toddlers. Child Development, 89(1), 27-36.

Mendoza, K. (2013). Protection and empowerment: Exploring parents' use of Internet mediation strategies with preteens. Temple University.

Modecki, K. L., Blomfield Neira, C., \& Barber, B. L. (2018). Finding what fits: Breadth of participation at the transition to high school mitigates declines in self-concept. Developmental Psychology, 54(10), 1954.
Modecki, K.L., Duvenage M., Uink, B., Barber, B., \& Donovan, C. $(2021$, a). When less is more but none is worse: Adolescent online coping. Clinical Psychological Science. https://doi.org/10.1177/21677026211028983

Modecki, K. L., Low-Choy, S., Vasco, D., Vernon, L., \& Uink, B. (2021, b). Commentary response: Smartphone use and parenting: re-stratifying the multiverse for families of young children. Journal of Child Psychology and Psychiatry.

Modecki, K. L., Low-Choy, S., Uink, B. N., Vernon, L., Correia, H., \& Andrews, K. (2020). Tuning into the real effect of smartphone use on parenting: a multiverse analysis. Journal of Child Psychology and Psychiatry, 61(8), 855-865.

Moher, D., Liberati, A., Tetzlaff, J., Altman, D. G., \& Prisma Group. (2009). Preferred reporting items for systematic reviews and meta-analyses: the PRISMA statement. PLoS medicine, 6(7), e1000097.

Moreno, M. A., \& Uhls, Y. T. (2019). Applying an affordances approach and a developmental lens to approach adolescent social media use. Digital Health, 5, 2055207619826678.

Nielsen, P., Favez, N., Liddle, H., \& Rigter, H. (2019). Linking parental mediation practices to adolescents' problematic online screen use: A systematic literature review. Journal of Behavioral Addictions, $8(4)$, 649-663. https://doi.org/10.1556/2006.8.2019.61

Nikken, P., \& Jansz, J. (2006). Parental mediation of children's videogame playing: A comparison of the reports by parents and children. Learning, Media and Technology, 31(2), 181-202.

Noble, S. U. (2018). Algorithms of oppression. New York University Press.

Ofcom (2020, June). Online Nation 2020 Report. Available from https://www.ofcom.org.uk/ data/assets/pdf_file/0027/196407/online-nation-2020-report.pdf

Ofcom (2017, November) . Children and Parents: Media Use and Attitudes Report 2017. Available from https://www.ofcom.org.uk/_data/assets/pdf_file/0020/108182/children-parents-media-use-attitudes-2017.pdf

Orben, A., \& Przybylski, A. K. (2019, a). Screens, teens, and psychological well-being: Evidence from three time-use-diary studies. Psychological Science, 30(5), 682-696.

Orben, A., \& Przybylski, A. K. $(2019$, b). The association between adolescent well-being and digital technology use. Nature Human Behaviour, 3(2), 173-182.

Orben, A. (2020a). Teenagers, screens and social media: a narrative review of reviews and key studies. Social Psychiatry and Psychiatric Epidemiology, 55(4), 407-414.

Orben, A. (2020b). The Sisyphean cycle of technology panics. Perspectives on Psychological Science, 15(5), 1143-1157.

Odgers, C. L. (2019). Why digital tools have not yet revolutionized adolescent health research and what we can do. Journal of Research on Adolescence, 29(3), 675-681.

Odgers, C. (2018). Smartphones are bad for some teens, not all. $\mathrm{Na}$ ture, 22, 432-434. doi: 10.1038/d41586-018-02109-8

Odgers, C. L., \& Jensen, M. R. (2020). Annual Research Review: Adolescent mental health in the digital age: facts, fears, and future directions. Journal of Child Psychology and Psychiatry, 61(3), 336-348.

Olweus, D. (2012). Cyberbullying: An overrated phenomenon?. European Journal of Developmental Psychology, 9(5), 520-538.

Ouzzani, M., Hammady, H., Fedorowicz, Z., \& Elmagarmid, A. (2016). Rayyan-a web and mobile app for systematic reviews. Systematic Reviews, 5, 210. 
Pater, J.A., Miller, A., and Mynatt, E.D. (2015). This digital life: A neighborhood-based study of adolescents' lives online. In Proceedings of the 33rd Annual ACM Conference on Human Factors in Computing Systems, 2305-14. https://doi.org/10.1145/2702123.2702534.

Pina, L. R., Gonzalez, C., Nieto, C., Roldan, W., Onofre, E., \& Yip, J. C. (2018). How Latino children in the US engage in collaborative online information problem solving with their families. Proceedings of the ACM on Human-Computer Interaction, 2(CSCW), 1-26.

Radesky, J. S., Eisenberg, S., Kistin, C. J., Gross, J., Block, G., Zuckerman, B., \& Silverstein, M. (2016). Overstimulated consumers or next-generation learners? Parent tensions about child mobile technology use. The Annals of Family Medicine, 14(6), 503-508.

Rhim, J., Lee, S., Lee, S., Na, J. W., \& Doh, Y. Y. (2016). Mutual Rule-Shaping with Parents to Form Adolescents' Healthy Smartphone Use. Annual Review of Cybertherapy and Telemedicine, 102.

Rickman, A. N. (2013). Living docility and dissent: US small town girls' social media use within social marginalization. University of Illinois at Urbana-Champaign.

Roth, G., Assor, A., Niemiec, C. P., Ryan, R. M., \& Deci, E. L. (2009). The emotional and academic consequences of parental conditional regard: Comparing conditional positive regard, conditional negative regard, and autonomy support as parenting practices. Developmental Psychology, 45(4), 1119.

Schlesinger, A., Edwards, W. K., \& Grinter, R. E. (2017, May). Intersectional HCI: Engaging identity through gender, race, and class. In Proceedings of the 2017 CHI conference on human factors in computing systems (pp. 5412-5427).

Smetana, J. G., \& Asquith, P. (1994). Adolescents' and parents' conceptions of parental authority and personal autonomy. Child Development, 65(4), 1147-1162.

Smetana, J., Crean, H. F., \& Campione-Barr, N. (2005). Adolescents' and parents' changing conceptions of parental authority. New Directions for Child and Adolescent Development, 2005(108), 31-46.

Smetana, J. G., Metzger, A., Gettman, D. C., \& Campione-Barr, N. (2006). Disclosure and secrecy in adolescent-parent relationships. Child Development, 77(1), 201-217.

Soenens, B., Vansteenkiste, M., Lens, W., Luyckx, K., Goossens, L., Beyers, W., \& Ryan, R. M. (2007). Conceptualizing parental autonomy support: Adolescent perceptions of promotion of independence versus promotion of volitional functioning. Developmental Psychology, 43(3), 633.

Solecki, S. M. (2016). An exploratory study on parental monitoring of adolescent cell phone use. Drexel University.

Sugie, N. F. (2018). Utilizing smartphones to study disadvantaged and hard-to-reach groups. Sociological Methods \& Research, 47(3), 458-491.

Symons, K., Ponnet, K., Walrave, M., \& Heirman, W. (2017). A qualitative study into parental mediation of adolescents' internet use. Computers in Human Behavior, 73, 423-432.

Taffel, S. (2016). Perspectives on the postdigital: Beyond rhetorics of progress and novelty. Convergence, 22(3), 324-338.

Tokić, A., \& Pećnik, N. (2011). Parental behaviors related to adolescents' self-disclosure: Adolescents' views. Journal of Social and Personal Relationships, 28(2), 201-222.

Twenge, J. M. (2019). More time on technology, less happiness? Associations between digital-media use and psychological wellbeing. Current Directions in Psychological Science, 28(4), 372379 .
Twenge, J. M., Joiner, T. E., Rogers, M. L., \& Martin, G. N. (2018). Increases in depressive symptoms, suicide-related outcomes, and suicide rates among US adolescents after 2010 and links to increased new media screen time. Clinical Psychological Science, 6(1), 3-17.

Updegraff, K. A., McHale, S. M., Whiteman, S. D., Thayer, S. M., \& Crouter, A. C. (2006). The nature and correlates of MexicanAmerican adolescents' time with parents and peers. Child Development, 77(5), 1470-1486.

Valkenburg, P. M., Krcmar, M., Peeters, A. L., \& Marseille, N. M. (1999). Developing a scale to assess three styles of television mediation: "Instructive Mediation," "Restrictive Mediation," and "Social Coviewing." Journal of Broadcasting \& Electronic Media, 43(1), 52. https://doi.org/10.1080/08838159909364474

Valkenburg, P. M., Piotrowski, J. T., Hermanns, J., \& De Leeuw, R. (2013). Developing and validating the perceived parental media mediation scale: A self-determination perspective. Human Communication Research, 39(4), 445-469.

Valkenburg, P.M., van Driel, I.I., \& Beyens, I..(2021). The associations of active and passive social media use with well-being: A critical scoping review. PsyArXiv, May 7, 2021. https://doi.org/10.31234/osf.io/j6xqz

Verduyn P, Gugushvili N, Massar K, et al. (2020) Social comparison on social networking sites. Current Opinion in Psychology 36: 32-37.

Vernon, L. (2019). Time-use for the iGeneration: A person-centered approach. Human Behavior and Emerging Technologies, 1(2), 91-102.

Vieno, A., Nation, M., Pastore, M., \& Santinello, M. (2009). Parenting and antisocial behavior: a model of the relationship between adolescent self-disclosure, parental closeness, parental control, and adolescent antisocial behavior. Developmental Psychology, 45(6), 1509.

Viner, R., Davie, M., \& Firth, A. (2019). The health impacts of screen time: A guide for clinicians and parents. Royal College of Paediatrics and Child Health.

Vijayakumar, N., \& Pfeifer, J. H. (2020). Self-disclosure during adolescence: Exploring the means, targets, and types of personal exchanges. Current Opinion in Psychology, 31, 135-140.

Vogels, E. (2021, June). Digital divide persists even as Americans with lower incomes make gains in tech adoption. Pew Research Center. http://www.pewresearch.org/facttank/2021/06/22/digital-divide-persists-even-as-americans-with-lower-incomesmakegains-in-tech-adoption/

Vongkulluksn, W. (2016). Parental Mediation of Adolescents' Technology Use at Home (Doctoral dissertation, University of Southern California).

Wang, R., Bianchi, S. M., \& Raley, S. B. (2005). Teenagers' Internet use and family rules: A research note. Journal of Marriage and Family, 67(5), 1249-1258.

Wartella, E. A., \& Jennings, N. (2000). Children and computers: New technology. Old concerns. The Future of Children, 31-43.

Wisniewski, P., Ghosh, A. K., Xu, H., Rosson, M. B., Carroll, J. M., \& Assoc Comp, M. (2017). Parental Control vs. Teen SelfRegulation: Is there a middle ground for mobile online safety? (WOS:000455087800005). https://doi.org/10.1145/2998181.2998352

Yardi, S., \& Bruckman, A. (2012, May). Income, race, and class: exploring socioeconomic differences in family technology use. In Proceedings of the SIGCHI Conference on Human Factors in Computing Systems (pp. 3041-3050). 
Supplement 1. Search Strategies

Databases

Ovid Medline, Web of Science, PsycINFO, the Educational Resources Information Centre (ERIC), Proquest Dissertations and Theses, and ACM Digital Library

$\underline{\text { Limits }}$

Year: 2008 forward

Publication type: Peer-reviewed journal article, dissertation/thesis, conference paper / proceedings, book, or book chapter

Language: English

$\underline{\text { Search Parameters }}$

Ovid Medline:

(exp Internet/ OR exp Cell Phone/ OR computer mediated communication*.ti,ab. OR Social Media.ti,ab. OR Internet.ti,ab. OR SNS.ti,ab. OR social networking site*.ti,ab. OR Social network site*.ti,ab. OR cyber.ti,ab. OR online.ti,ab. OR Cell phone.ti,ab. OR Cell phones.ti,ab. OR mobile phone.ti,ab. OR Mobile phones.ti,ab. OR Digital.ti,ab. OR Smartphone.ti,ab. OR Smartphones.ti,ab. OR GPS.ti,ab. OR Digital media.ti,ab. OR CMC.ti,ab.)

AND

(exp Adolescent/ OR exp Child/ OR Adolescent.ti,ab. OR Adolescents.ti,ab. OR Juvenile.ti,ab. OR Juveniles.ti,ab. OR Teen.ti,ab. OR Teens.ti,ab. OR Teenagers.ti,ab. OR Youth.ti,ab. OR Child.ti,ab. OR Children.ti,ab. OR Childrens.ti,ab.)

AND

((Parenting OR Parent OR Parental OR Family) adj3 (Mediation OR Restriction OR Monitoring OR Involvement OR Support OR Rules OR Supervision OR Limit OR Control)).ti,ab.

Web of Science:

(Internet OR "Cell Phone" OR "computer mediated communication*" OR "Social Media" OR Internet OR SNS OR "social networking site*" OR "Social network site*" OR cyber OR online OR "Cell phone" OR "Cell phones" OR "mobile phone" OR "Mobile phones" OR Digital OR Smartphone OR Smartphones OR GPS OR "Digital media" OR CMC)

AND

(Adolescent OR Child OR Adolescent OR Adolescents OR Juvenile OR Juveniles OR Teen OR Teens OR Teenagers OR Youth OR Child OR Children OR Childrens)

AND

((Parenting OR Parent OR Parental OR Family) NEAR/3 (Mediation OR Restriction OR Monitoring OR Involvement OR Support OR Rules OR Supervision OR Limit OR Control))

PsycINFO:

(Internet OR "Cell Phone" OR computer mediated communication*.ti,ab OR Social Media.ti,ab OR Internet.ti,ab OR SNS.ti,ab OR social networking site*.ti,ab OR Social network site*.ti,ab OR cyber.ti,ab OR online.ti,ab OR Cell phone.ti,ab OR Cell phones.ti,ab OR mobile phone.ti,ab OR Mobile phones.ti,ab OR Digital.ti,ab OR Smartphone.ti,ab OR Smartphones.ti,ab OR GPS.ti,ab OR Digital media.ti,ab OR CMC.ti,ab) AND

(Adolescent OR Child OR Adolescent.ti,ab OR Adolescents.ti,ab OR Juvenile.ti,ab OR Juveniles.ti,ab OR Teen.ti,ab OR Teens.ti,ab OR Teenagers.ti,ab OR Youth.ti,ab OR Child.ti,ab OR Children.ti,ab OR Childrens.ti,ab)

AND

((Parenting.ti,ab OR Parent.ti,ab OR Parental.ti,ab OR Family.ti,ab) ADJ3 (Mediation.ti,ab OR Restriction.ti,ab OR Monitoring.ti,ab OR Involvement.ti,ab OR Support.ti,ab OR Rules.ti,ab OR Supervision.ti,ab OR Limit.ti,ab OR Control.ti,ab)) 
Educational Resources Information Centre (ERIC):

(Internet OR "Cell Phone" OR "computer mediated communication*" OR "Social Media" OR Internet OR SNS OR "social networking site*" OR "Social network site*" OR cyber OR online OR "Cell phone" OR "Cell phones" OR "mobile phone" OR "Mobile phones" OR Digital OR Smartphone OR Smartphones OR GPS OR "Digital media" OR CMC)

AND

(Adolescent OR Child OR Adolescent OR Adolescents OR Juvenile OR Juveniles OR Teen OR Teens OR Teenagers OR Youth OR Child OR Children OR Childrens)

AND

(Parenting OR Parent OR Parental OR Family)

AND

(Mediation OR Restriction OR Monitoring OR Involvement OR Support OR Rules OR Supervision OR Limit OR Control)

Proquest Dissertations and Theses:

(Internet OR "Cell Phone" OR "computer mediated communication*" OR "Social Media" OR Internet OR SNS

OR "social networking site*" OR "Social network site*" OR cyber OR online OR "Cell phone" OR "Cell phones"

OR "mobile phone" OR "Mobile phones" OR Digital OR Smartphone OR Smartphones OR GPS OR "Digital media" OR CMC)

AND

(Adolescent OR Child OR Adolescent OR Adolescents OR Juvenile OR Juveniles OR Teen OR Teens OR Teenagers OR Youth OR Child OR Children OR Childrens)

AND

(Parenting OR Parent OR Parental OR Family)

AND

(Mediation OR Restriction OR Monitoring OR Involvement OR Support OR Rules OR Supervision OR Limit OR Control)

ACM Digital Library (*Include SIGCHI conferences*):

(Internet OR "Cell Phone" OR "computer mediated communication*" OR "Social Media" OR Internet OR SNS OR "social networking site*" OR "Social network site*" OR cyber OR online OR "Cell phone" OR "Cell phones"

OR "mobile phone" OR "Mobile phones" OR Digital OR Smartphone OR Smartphones OR GPS OR "Digital media" OR CMC)

AND

(Adolescent OR Child OR Adolescent OR Adolescents OR Juvenile OR Juveniles OR Teen OR Teens OR Teenagers OR Youth OR Child OR Children OR Childrens)

AND

(Parenting OR Parent OR Parental OR Family)

AND

(Mediation OR Restriction OR Monitoring OR Involvement OR Support OR Rules OR Supervision OR Limit OR Control)

Supplement 2. Definitions of themes emerging from qualitative studies and associated frequencies (number of papers with at least one instance of a given theme, not mutually exclusive).

\section{Restriction and Rule Setting}

- Rule Setting: $(\mathrm{N}=47)$ Parents setting rules, such as screen time limits but without actively enforcing these limits with tech. This sometimes happened as a result of balancing technology use with other activities, such as homework and extracurricular activities. 
- Reward/Punishment: $(\mathrm{N}=42)$ Parents noting that tech is used as a reward or taken away as a punishment. Often parents leverage material/financial support to control usage.

- Tech Restriction: $(\mathrm{N}=34)$ Parents limiting the use of technology through by restricting features within that technology. e.g., locking down features

- Physical Restriction: (N=25) Restricting physical access to the device or defining appropriate use based on the device

- Peer Restriction: $(\mathrm{N}=10)$ restricting access to peers based on peers' tech use or what they post/have access to tech wise; friending peers to keep track; changing rules based on peer presence

\section{Parental Monitoring}

- Active: $(\mathrm{N}=27)$ Monitoring on an on-going basis, such as friending your child on Facebook (though limited view). Social media stalking

- Intermittent: $(\mathrm{N}=24)$ Parents getting access to the device on-demand to review activities

- Technological: $(\mathrm{N}=9)$ Using parental control apps and other technologies for monitoring.

- Privacy and Trust: $(\mathrm{N}=24)$ Negotiating between trusting the child versus respecting their privacy

\section{Parental Mediation}

- Active: (N=57) Consistently keeping the lines of communication open/providing support. Teaching and giving guidelines and working to help a child learn how to be a "decent individual involving technology use" Being actively involved in your child's online life.

- Intermittent: ( $\mathrm{N}=32)$ When parents passively tell their children advice, like "You should go to bed," to mediate tech use. More reactive than active.

- Parenting by Example: ( $\mathrm{N}=21$ ) The idea that parents should model healthy tech use for their children to teach them healthy tech use. Often this points out how parents over-use tech as well.

\section{Parent teen Boundary Negotiation}

- Work arounds: $(\mathrm{N}=54)$ Child not listening to their parents or working around tech rules via another vehicle, such as borrowing tech from others.

- Boundary Tensions: ( $\mathrm{N}=22)$ Parent/child conflict over tech use, as well as negotiating boundaries

\section{Alternative Perspectives to Parenting Tech}

- Digital Opportunities: ( $\mathrm{N}=31)$ Tech a pathway for future success and safety but also a potential disadvantage for those from cultural/low SES background who may not have access to the latest tech.

- Social Learning: $(\mathrm{N}=20)$ Using technology in a way that promotes the child's social learning and communication skills

6. Other Social Ecologies of Support

- Extended Family/ Friends' Parents: $(\mathrm{N}=12)$ Extended family of friends' parents helping look out after a child on social media

- Sibling Influence. ( $\mathrm{N}=10)$ Siblings influencing technology use in the home. Involves siblings or other family members helping monitor.

- School-Related. ( $\mathrm{N}=6$ ) School-based restrictions and/or tensions between parents and schools regarding tech 